\title{
GENETIC VARIANTS OF HUMAN SERUM CHOLINESTERASE INFLUENCE METABOLISM OF THE MUSCLE RELAXANT SUCCINYLCHOLINE
}

\author{
OKSANA LOCKRIDGE \\ Pharmacology Department, Medical Science I, M6322, University of Michigan Medical School, \\ Ann Arbor, MI 48109-0626, U.S.A.
}

\begin{abstract}
People with genetic variants of cholinesterase respond abnormally to succinylcholine, experiencing substantial prolongation of muscle paralysis with apnea rather than the usual 2-6 min. The structure of usual cholinesterase has been determined including the complete amino acid and nucleotide sequence. This has allowed identification of altered amino acids and nucleotides. The variant most frequently found in patients who respond abnormally to succinylcholine is atypical cholinesterase, which occurs in homozygous form in 1 out of 3500 Caucasians. Atypical cholinesterase has a single substitution at nucleotide 209 which changes aspartic acid 70 to glycine. This suggests that Asp 70 is part of the anionic site, and that the absence of this negatively charged amino acid explains the reduced affinity of atypical cholinesterase for positively charged substrates and inhibitors. The clinical consequence of reduced affinity for succinylcholine is that none of the succinylcholine is hydrolyzed in blood and a large overdose reaches the nerve-muscle junction where it causes prolonged muscle paralysis. Silent cholinesterase has a frame shift mutation at glycine 117 which prematurely terminates protein synthesis and yields no active enzyme. The $\mathbf{K}$ variant, named in honor of $\mathbf{W}$. Kalow, has threonine in place of alanine 539 . The $\mathrm{K}$ variant is associated with $33 \%$ lower activity. All variants arise from a single locus as there is only one gene for human cholinesterase (EC 3.1.1.8). Comparison of amino acid sequences of esterases and proteases shows that cholinesterase belongs to a new family of serine esterases which is different from the serine proteases.
\end{abstract}

\section{CONTENTS}

1. Introduction 36

1.1. Use of succinylcholine led to discovery of atypical cholinesterase 36

1.2. Definition of cholinesterase 36

2. Clinical Aspects $\quad 37$

2.1. Role of cholinesterase in determining fate and action of succinylcholine 37

2.2. Genetic variants of cholinesterase

2.3. Ethnic distribution of genetic variants 39

2.4. Relation between dose of succinylcholine and duration of apnea 39

2.5. Not all cases of prolonged apnea following the use of succinylcholine can be explained by genetic variants of serum cholinesterase

2.6. Phenotyping procedures

2.6.1. Phenotyping by dibucaine number

2.6.2. Importance of nerve stimulator

2.6.3. Polymerase chain reaction followed by DNA sequencing

2.8. Other esterases involved in drug metabolism

3. The Usual Cholinesterase Protein 45

3.1. Purification of usual cholinesterase protein 45

3.2. Specific activity of electrophoretically pure cholinesterase 45

3.3. Molecular weight $\quad 45$

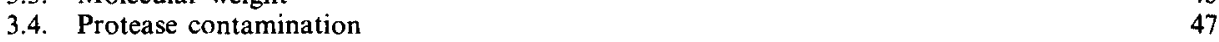

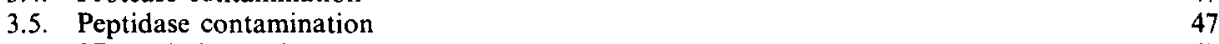

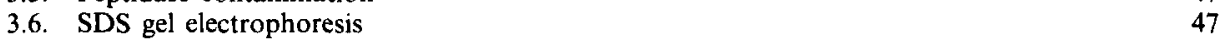

3.7. Amino acid sequence $\quad 48$

3.8. Disulfide bonds 49

3.9. Carbohydrates 4

3.10. Subunit organization $\quad 50$

3.11. Active site $\quad 50$

4. Family of Serine Esterases $\quad 50$ 
5. The Usual Cholinesterase Gene

5.1. cDNA sequence $\quad 52$

5.2. $5^{\prime}$ region $\quad 52$

5.3. 3' region

5.4. One cholinesterase gene 52

5.5. Location on chromosome 3

5.6. Cholinesterase in various tissues

6. Atypical Cholinesterase

6.1. Purification of atypical cholinesterase protein 53

6.2. Specific activity of atypical cholinesterase $\quad 53$

6.3. Atypical cholinesterase mutation affects the binding of positively charged ligands 54

6.4. Location of nucleotide alteration in atypical cholinesterase 55

6.5. Atypical cholinesterase mutation affects the binding of neutral ligands 55

6.6. Atypical cholinesterase mutation affects the binding of negatively charged ligands 56

7. The $\mathrm{K}$ Variant

8. Silent Cholinesterase

8.1. Location of nucleotide alteration in silent cholinesterase

9. Questions that Remain Unanswered or Controversial

Acknowledgements

References $\quad 57$

\section{INTRODUCTION}

\subsection{USE OF SUCCINYLCHOLINE LED TO DISCOVERY of ATYPICAL Cholinesterase}

Succinylcholine was introduced for use as a muscle relaxant in 1951 because it produced prompt and complete paralysis, was followed by rapid recovery, and seemed free from toxic side-effects. A problem was soon noticed. In some patients the duration of action was much longer than expected; muscle paralysis could last for hours rather than the usual 2-6 min. These patients were unable to breathe and had to be maintained on mechanical ventilators. While the cause of this abnormal response was suspected to be an abnormal cholinesterase it was not until 1956, when Werner Kalow first described the atypical cholinesterase variant, that a biochemical basis was provided for the clinical observation. Kalow reported that the abnormal response was due to an atypical serum cholinesterase whose affinity for succinylcholine was so low that it failed to hydrolyze any of the injected succinylcholine. Kalow and Staron (1957) showed that atypical cholinesterase was a heritable trait. Thus, the genetic basis of the abnormal response was established, and the field of pharmacogenetics was born.

In the 33 years since the discovery of atypical cholinesterase, the basic concepts introduced by Kalow remain unchanged and have been strengthened by analysis of several hundred thousand blood samples in laboratories throughout the world. It is accepted that a person who has atypical cholinesterase will always respond with prolonged apnea if he receives a standard dose of succinylcholine. The phenotyping procedure introduced by Kalow and Genest (1957), which includes determination of dibucaine number, is the most widely used method today. Kalow's observations that atypical cholinesterase is defective in its ability to bind positively charged esters and that atypical cholinesterase is an inherited trait have been confirmed in many laboratories. The interpretation (Kalow and Davies, 1958) that atypical cholinesterase has an amino acid alteration at the anionic binding site is supported by recent DNA sequencing results.
Since the publication of Kalow's book in 1962, Pharmacogenetics, Heredity and the Response to Drugs, additional genetic variants of cholinesterase have been recognized. Population distributions of the most readily identifiable variants, the atypical and silent, have been done on most continents. More drugs have been added to the list of esters hydrolyzed by cholinesterase, and more cholinesterase inhibitors have been identified. Reviews which focus on clinical experience with succinylcholine and correlate prolonged apnea with cholinesterase are by Whittaker (1980) and Viby-Mogensen (1983). The review by Harris (1980) explains how a small number of genetic variants may underlie the continuously graded variation in cholinesterase activity. Brown et al. (1981) review the cholinesterase variants, succinylcholine apnea, clinical applications of activity measurements, detection methods for variants, and the biochemical properties of cholinesterase. The monograph by Whittaker (1986) covers the genetic variants of cholinesterase, their biochemical properties, occurrence, ethnic distribution, methods for phenotyping genetic variants, and the level of cholinesterase in various diseases. The present review focusses on new information since Whittaker's monograph. The complete amino acid sequence of usual cholinesterase has been determined, as well as the location of disulfide bonds and carbohydrate chains. The cDNA clone of usual cholinesterase has been isolated and sequenced. The cholinesterase gene has been isolated and mapped and it has been shown that there is only one cholinesterase gene. Finally, the nucleotide alterations in the genes coding for atypical, one type of silent, and the $K$ variant of cholinesterase have been determined.

\subsection{Definition of Cholinesterase}

The cholinesterase discussed here is EC 3.1.1.8, acylcholine acyhydrolase. Other names are butyrylcholinesterase, pseudocholinesterase, and nonspecific cholinesterase. Cholinesterase is distinguished from a related enzyme called acetylcholinesterase (EC 3.1.1.7) or true cholinesterase, by substrate preference, inhibitor specificity, and by antibody recogni- 
tion (Brimijoin and Hammond, 1988). Human plasma and serum are a rich source of cholinesterase, whereas human red blood cell membranes are a source of acetylcholinesterase.

\section{CLINICAL ASPECTS}

\subsection{Role of Cholinesterase in Determining Fate AND ACTION OF SUCCINYLCHOLINE}

Succinylcholine is hydrolyzed by cholinesterase to form succinylmonocholine and choline. While the diester is a powerful muscle relaxant, the monoester has little pharmacologic activity. When succinylcholine is injected intravenously about $90 \%$ of an ordinary dose is hydrolyzed by cholinesterase within 1 min (Kalow, 1962a). Thus the actual dose of succinylcholine that reaches the nerve-muscle junction is far smaller than the injected dose. At the nerve-end plate succinylcholine binds to a receptor with the result that the nerve-end plate is depolarized and loses sensitivity to the neurotransmitter acetylcholine, causing the patient to experience complete muscle paralysis. Duration of neuromuscular block can be monitored with precision by using an electric nerve stimulator (Viby-Mogensen, 1983).

Recovery from succinylcholine is rapid if the dose of succinylcholine that reaches the nerve-end plate is low. However, a dose producing an effect normally lasting $2 \mathrm{~min}$ produces in the absence of hydrolysis by cholinesterase an apnea of about $1 \mathrm{hr}$ (Kalow and Gunn, 1957). Muscle paralysis prolonged much beyond an hour probably represents abnormalities or interferences at the neuromuscular end plate unless a very large dose of succinylcholine is injected. Recovery does not begin until most of the succinylcholine has been hydrolyzed or cleared from blood and extracellular fluid. During the period of complete paralysis a significant amount of succinylcholine is present in blood and extracellular fluid as can be inferred from the observation that injection of concentrated cholinesterase at this time, but at no other time, shortens the period of apnea (Viby-Mogensen, 1981b). After the blood and extracellular fluid have been cleared of succinylcholine the rate of recovery from apnea depends on the concentration of succinylcholine remaining at the nerve-end plate, that is, on the number of receptors occupied, and on the rate of diffusion of succinylcholine away from the nerveend plate. The importance of extracellular fluid as a compartment containing both succinylcholine and cholinesterase is supported by measurements of volume of distribution. Following intravenous injection of purified cholinesterase, the volume of distribution was $18 \%$ of body weight, or about $13 \mathrm{~L}$ for a $70 \mathrm{~kg}$ person (Ostergaard et al., 1988). This $13 \mathrm{~L}$ includes $2.8 \mathrm{~L}$ total blood volume and $10.5 \mathrm{~L}$ total extracellular fluid volume.

The nerve-end plate is normal in people who have atypical cholinesterase as indicated by their normal response to decamethonium and D-tubocurarine (Kalow, 1962a,b), two neuromuscular blocking drugs that have no ester bonds and are not hydrolyzed by cholinesterase. Further evidence supporting this point comes from Kalow and Gunn (1957) who showed that a plot of log dose succinylcholine versus $\log$ min of apnea gave a series of parallel lines (Fig. 1). The slope of this line was identical in all persons regardless of their cholinesterase genotype or level of cholinesterase activity. The constant slope indicated that doubling the dose of succinylcholine increased the duration of apnea by a factor of 1.5 in all cholinesterase genotypes. The constant slope also meant that termination of apnea depended on a common process such as diffusion of succinylcholine away from the nerve-end plate, and that cholinesterase had no effect on the rate of diffusion (Kalow, 1962b).

The exaggerated response by people with atypical cholinesterase is explained by the inability of atypical cholinesterase to hydrolyze succinylcholine. Atypical cholinesterase has a low affinity for succinylcholine so that it does not bind succinylcholine when the succinylcholine concentration is in the pharmacologic range. In test tube experiments where the succinylcholine concentration can be raised to saturating levels, atypical cholinesterase hydrolyzes succinylcholine with the same extrapolated maximal velocity as usual cholinesterase. The consequence of atypical cholinesterase's low affinity for succinylcholine is that none of the administered drug is hydrolyzed in blood. Therefore, the nerve-end plate receives a 50-100-fold overdose of succinylcholine (Kalow, 1962a, b).

Cholinesterase has no effect on succinylcholine once the drug is at the nerve-end plate. This is demonstrated by the fact that injection of concentrated cholinesterase has no pronounced effect on the duration of apnea when cholinesterase is administered late, approximately $90 \mathrm{~min}$ after a single dose of succinylcholine (Viby-Mogensen, 1981b) in a person with the atypical genotype. The proper time for cholinesterase injection can be determined by using a nerve stimulator (Viby-Mogensen, 1983).

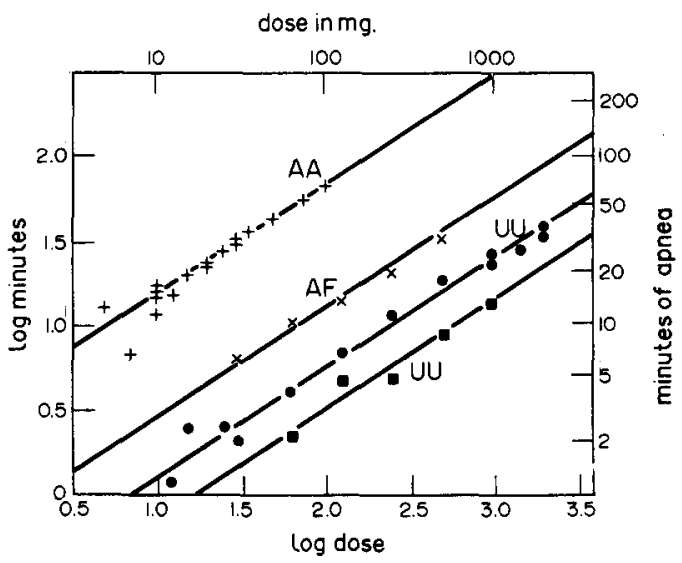

FIG. 1. Logarithmic plot of the relation between dose of succinylcholine chloride and duration of apnea. Data are for one person with atypical cholinesterase (AA), one heterozygote (AF), one person with a low level of usual cholinesterase (UU), and one with a high level of usual cholinesterase (UU). The parallel lines indicate that neither the amount of cholinesterase nor the genotype affect the rate of recovery from succinylcholine apnea once succinylcholine is at the nerve end plate (Kalow and Gunn, 1957). Reprinted with the permission of the authors and the copyright holder, The American Society for Pharmacology and Experimental Therapeutics, Bethesda. 
Treatment of succinylcholine apnea with commercially purified, concentrated cholinesterase has been extensively tested at the Danish Cholinesterase Research Unit, and though this treatment is effective it is not recommended for routine use (VibyMogensen, 1983). One reason is that the injected cholinesterase works only if it is administered at the right time; given late, it has little or no effect. A second reason is its expense. A third reason is the risk of infection from a human blood product.

When nerve stimulation shows presence of a phase II block, neostigmine can be used to shorten block. Neostigmine can shorten block even though it is an anticholinesterase drug, because during phase II block its effect is not on cholinesterase. Instead neostigmine stimulates the end plate to overcome the nondepolarizing, phase II block. If neostigmine is given before succinylcholine or while succinylcholine is still in blood, it inhibits cholinesterase with the result that apnea is prolonged (Viby-Mogensen, 1983).

\subsection{Genetic Variants of Cholinesterase}

Because DNA sequencing has revealed the precise location of nucleotide alterations in some of these variants, and multiple nucleotide substitutions within one variant are likely to be revealed in the near future, a more precise nomenclature is introduced in Table 1. The descriptive name is followed by the affected amino acid, its position in the mature protein, and the altered amino acid. Another proposed modification to the nomenclature is elimination of the terms E1 and E2 which refer to two cholinesterase loci. As there is only one gene for human cholinesterase (located on the long arm of chromosome 3 at q21-25), all cholinesterase genotypes must arise from this locus. Abbreviations can be simplified by calling homozygotes UU, AA, SS, FF, KK, JJ, and HH. Heterozytes can be abbreviated to show two of these alleles, for example
UA for usual-atypical. Silent is called Silent-1 because we anticipate that additional silent variants will be identified. The next silent will be called Silent-2. In the future some variants may be shown to arise from nucleotide alterations in untranslated regions, for example in the regulatory regions of the gene. These can be designated by nucleotide numbers.

The genetic variant most often found in patients who have an abnormal response to succinylcholine is atypical cholinesterase, AA. The silent allele was first proposed by Liddell et al. (1962) and confirmed by many laboratories (Altland and Goedde, 1970; Rubinstein et al., 1970). Silent cholinesterase has $0-2 \%$ of normal activity. The fluoride variant was recognized by Harris and Whittaker (1961) who used $\mathrm{NaF}$ inhibition to identify the AF phenotype. The $\mathrm{H}, \mathrm{J}$, and $\mathrm{K}$ variants are quantitative variants. Despite their reduced activity they are indistinguishable from usual cholinesterase (UU) in UH, UJ, and UK phenotypes, but are detectable when they occur in heterozygote combination with atypical cholinesterase ( $\mathrm{AH}, \mathrm{AJ}$, and $\mathrm{AK})$. The $\mathrm{H}$ variant has been found in two families and is associated with a greater than $90 \%$ decrease in activity similar to the low activity in silent cholinesterase (Whittaker and Britten, 1987). The $J$ variant has a frequency of 1 in 150,000 and is associated with a $66 \%$ decrease in activity (Garry et al., 1976; Evans and Wardell, 1984). The $\mathrm{K}$ variant has a frequency of $1 \%$ and is associated with a $33 \%$ decrease in activity (Rubinstein $e t$ al., 1978; Whittaker and Britten, 1985). Mildly prolonged apnea can occur in persons with UA or AK phenotypes. A longer apnea occurs in persons with AF, FS, or AJ phenotypes. The most pronounced effect of succinylcholine with the longest duration of muscle paralysis occurs in persons with the SS, AA, and AS genotypes (Viby-Mogensen, 1983).

One family in Newfoundland was found to have a rare variant recognized by a high percentage inhibition by dibucaine (Simpson and Elliott, 1981). The

TABLE 1. Genetic Variants of Cholinesterase

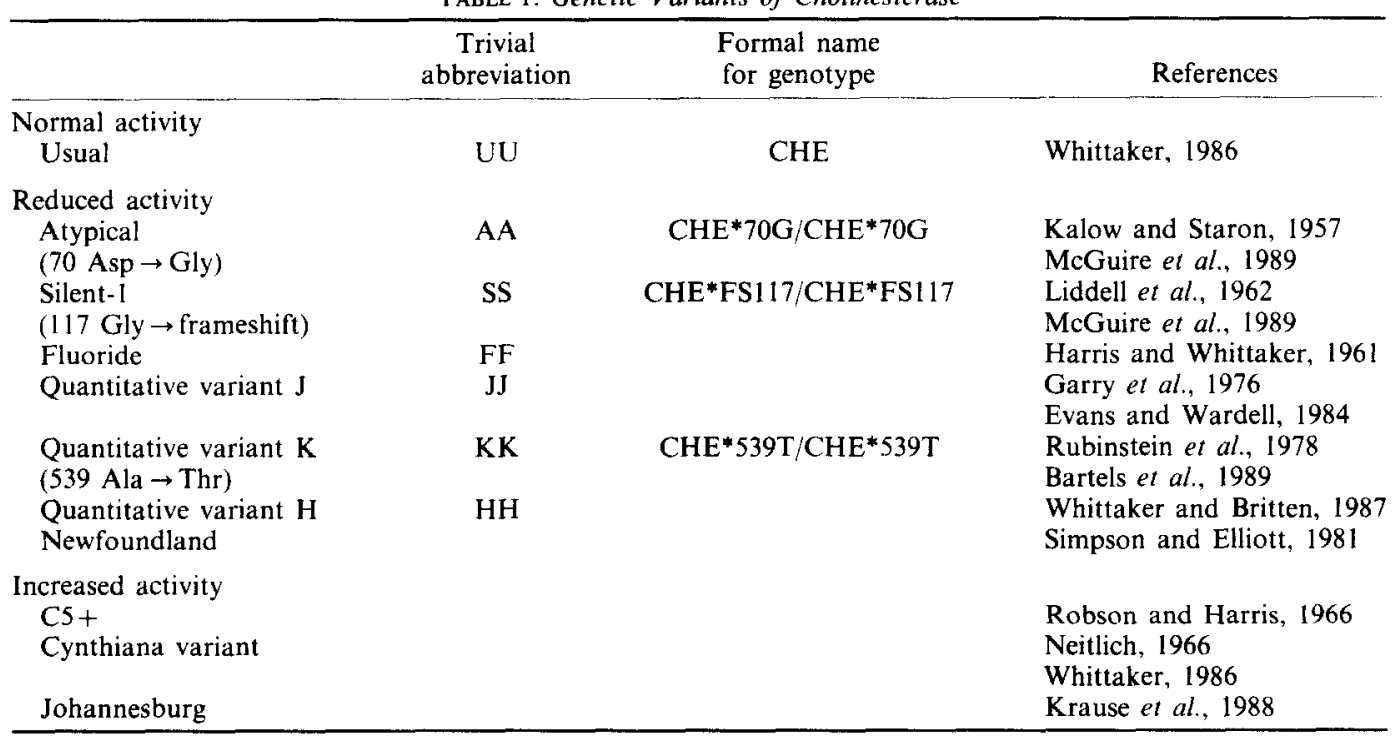

Formal names follow the rules of the Committee for Human Gene Nomenclature (Shows et al., 1987). 
proband, who was heterozygous for the Newfoundland and atypical alleles, was sensitive to succinylcholine.

Four families with higher than normal cholinesterase activity have been reported. These persons are resistant to succinylcholine. The high cholinesterase activity variant is called Cynthiana after its place of origin (Neitlich, 1966; Whittaker, 1986). A South African family descended from Dutch and German immigrants was found to have twice the normal activity (Krause et al., 1988) and a normal number of enzyme molecules. This distinguished the South African variant from the Cynthiana because the Cynthiana had increased activity accompanied by increased amount of cholinesterase protein.

The $\mathrm{C} 5+$ variant has an extra band on electrophoresis and is associated with up to $30 \%$ increase in activity (Robson and Harris, 1966). The literature has claimed that $\mathrm{C} 5+$ originates from a second cholinesterase locus, called E2. Recent results from our laboratory have shown, however, that there is only one gene for cholinesterase. Therefore a second cholinesterase locus does not exist. The $\mathrm{C} 5+$ band is probably an association between cholinesterase and a second as yet unidentified protein (Scott and Powers, 1974). The E2 locus may specify this second, modifying protein. The $\mathrm{C} 5+$ variant is not important to the anesthetist as it does not affect response to succinylcholine.

\subsection{Ethnic Distribution of Genetic Variants}

Most of the data are for atypical cholinesterase because this is the only variant that has reliably been identified in both heterozygote and homozygote forms. Whittaker (1986) presented a comprehensive summary of results for the entire world, including maps showing cholinesterase allele frequencies in various populations. The data below are from Whittaker (1986).

In European populations the average frequency of the atypical allele is 0.017 in a total of 36,000 individuals tested. A frequency of 0.017 means that 1 out of 3500 people is homozygous atypical. Groups that have a much higher frequency are the French in Toulouse (0.0299), some Greeks (0.0561) and Spaniards in Galicia (0.0279), Basque (0.0312), and Valencia (0.0732). A low frequency was found in Icelanders; out of 128 Icelanders tested, none had the atypical allele.

The Jews of Iraq and Iran have a high frequency of the atypical allele, 0.0473 and 0.0755 , out of 1057 and 159 people tested. This contrasts with Jews from Europe, North Africa, Yemen, Lebanon, and Syria who have the same gene frequency as the general European population. A frequency of 0.0755 means that 1 out of every 175 Iranian Jews is homozygous atypical, and that approximately 8 out of every 100 carry the atypical allele.

The lowest frequency of the atypical allele is in Orientals and African Negroes, where many groups had zero atypical alleles and where the average frequency of 0.0002 calculates to 1 homozygous atypical in 25 million people.

The silent allele is infrequent $(0.0003)$ in European populations, where only one out of 10 million is homozygous silent. In India the silent allele is rare in the general population, although one group, the Vysyas of Andhra Pradesh have an exceptionally high frequency of 0.112 . A high frequency of the silent allele (0.1114) was found in Alaskan Eskimos where out of 1603 people tested, 28 were homozygous silents and 301 were heterozygotes.

There are few estimates of the frequency of the fluoride variant. The gene appears to be rare. In European populations where it has been most studied, its frequency is 0.0021

Approximately 40,000 people have been tested for the $\mathrm{CS}+$ variant. It is present in $9 \%$ of Europeans, 3\% of Asians, $5 \%$ of Africans and 7\% of Americans.

\subsection{Relation Between Dose of Succinylcholine AND Duration OF APNEA}

Kalow and Gunn (1957) measured duration of apnea in a group of 60 physically healthy mental patients who were given succinylcholine before electroshock therapy. They carefully controlled their conditions to ensure reproducibility. A given dose consistently resulted in the same length of apnea in a particular person. Each patient received a different succinylcholine dose at intervals of days or weeks. A direct relationship was found between dose and duration of apnea and results for four patients of various cholinesterase genotypes are shown in Fig. 2.

Examples from Kalow and Gunn (1957) of the duration of apnea following a dose of $100 \mathrm{mg}$ succinylcholine are 3-6 min apnea in 51 persons with usual cholinesterase, 5-12 $\mathrm{min}$ apnea in 6 persons with usual-atypical cholinesterase, and 50-65 min apnea in 3 persons homozygous for atypical cholinesterase. While length of apnea was related to activity level in persons with usual cholinesterase, it was unrelated to cholinesterase activity level in persons with atypical cholinesterase, a result which supported the conclusion that atypical cholinesterase hydrolyzed none of the succinylcholine.

Viby-Mogensen (1981a) studied neuromuscular blockade in heterozygote patients who had received succinylcholine at a dose of $1 \mathrm{mg} / \mathrm{kg}$. The number of patients with each genotype and the mean time to $90 \%$ recovery of twitch height was as follows: $28 \mathrm{UA}$ (14.6 min), 8 US (12.4 min), 3 UF (12.0 min), $3 \mathrm{AF}$ $(30 \mathrm{~min})$, and $1 \mathrm{FS}(30 \mathrm{~min})$. Recovery in all heterozygotes was prolonged compared to patients with the normal cholinesterase genotype $(9.3 \mathrm{~min})$.

Duration of apnea in 70 patients with usual cholinesterase who received $1 \mathrm{mg}$ succinylcholine per $\mathrm{kg}$ body weight (Viby-Mogensen, 1980) was found to increase with decreasing plasma cholinesterase activity (Fig. 3). Persons with high activity had 4 min apnea, persons with normal activity had $6 \mathrm{~min}$ apnea, and persons with low activity had $8 \mathrm{~min}$ apnea. Even the lowest cholinesterase activity $(200 \mu \mathrm{mol}$ benzoylcholine per min per liter of plasma) had only $22 \mathrm{~min}$ apnea.

Succinylcholine can be given to people with atypical cholinesterase but the dose must be lowered to $1 \%$ of the normal dose to achieve $5 \mathrm{~min}$ of apnea. Cohen et al. (1970) found that $1 \mathrm{mg}$ succinylcholine 


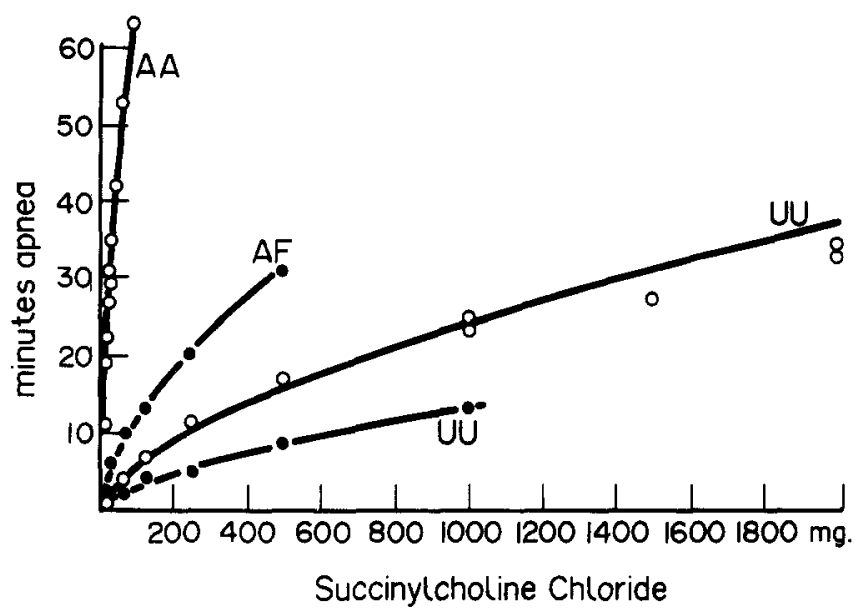

FIG. 2. Relation between dose of succinylcholine chloride and duration of apnea. Various doses were administered at intervals of days or weeks for electroshock treatment. The 4 representative patients have atypical (AA), atypical fluoride (AF), a low level of usual (UU), and a high level of usual cholinesterase (UU) (Kalow, 1962a, b). Reprinted with the permission of the author and the copyright holders, W. B. Saunders, Philadelphia and the Macmillan Publishing Company, New York.

resulted in $5 \mathrm{~min}$ apnea. Lee-Son et al. (1975) and Azar and Betcher (1981) administered a cumulative dose of $6-8 \mathrm{mg}$ to atypical cholinesterase patients who resumed spontaneous respiration $1-10 \mathrm{~min}$ after the last dose.

Under normal conditions, clinical doses of succinylcholine do not cross the placenta. However, in atypical homozygotic mothers, a clinical dose becomes a relative overdose which crosses the placental barrier and results in prolonged apnea of the newborn. In two case reports infants suffered transient respiratory depression when the mother's cholinesterase genotype was homozygous atypical and the infant's genotype was either homozygous atypical or atypical-usual (Baraka et al., 1975; Hoefnagel et al., 1979).

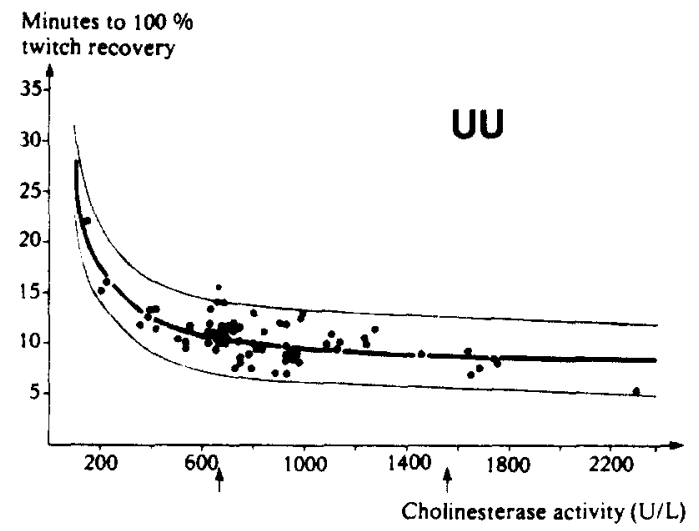

FIG. 3. Correlation between cholinesterase activity and time to recovery of $100 \%$ twitch height. 70 patients of the usual cholinesterase genotype received a dose of $1 \mathrm{mg} / \mathrm{kg}$ succinylcholine intravenously. Recovery of twitch was monitored by train-of-four nerve stimulation. The fitted regression line and $95 \%$ prediction region are shown. Arrows indicate the normal range of cholinesterase activity in genotypically normal patients (Viby-Mogensen, 1983). Reprinted with the permission of the author and the copyright holder, the Danish Medical Association, Copenhagen
2.5. Not all Cases of Prolonged Apnea Following THE USE OF SUCCINYLCHOLINE CAN BE EXPLAINED BY Genetic Variants of Serum Cholinesterase

The Danish Cholinesterase Research Unit tests sera of all persons in Denmark who respond abnormally to succinylcholine. A 4 year summary report of 225 cases (Viby-Mogensen and Hanel, 1978) showed that $64 \%$ of these cases had at least one abnormal cholinesterase gene, $6 \%$ had low cholinesterase activity due to an acquired deficiency (for example liver disease) while the remaining $28 \%$ had normal activity and normal genotype. Similarly, the Cholinesterase Research Unit in England directed by Mary Whittaker found that $65 \%$ of succinylcholine apneas were associated with genetic variants of cholinesterase (Whittaker, 1980). A summary of eight surveys reviewed by Whittaker (1980, 1986) shows that $65 \%$ of 1121 succinylcholinesensitive individuals carried at least one abnormal cholinesterase gene.

What explanations are available for the $35 \%$ who had the usual cholinesterase genotype, but nevertheless displayed unusually long periods of apnea after the administration of succinylcholine? In 77 succinylcholine-sensitive patients of genotype UU, prolonged apnea in 34 patients was due to factors other than standard use of succinylcholine (Viby-Mogensen and Hanel, 1978). These factors were hyperventilation or respiratory depression caused by overdose with an inhalation anesthetic or a nondepolarizing neuromuscular blocking agent, or succinylcholine overdose. In 14 cases prolonged apnea was explained by low cholinesterase activity; low activity was caused by liver diseases, chronic debilitating diseases, carcinoma, or by anticholinesterase drugs such as echothiopate eye drops. In 29 patients the reason for the prolonged apnea could not be established and the possibility existed that these cases represented unknown genotypes.

Reviews by Whittaker $(1980,1986)$ and VibyMogensen (1985) list causes of decreased plasma 
cholinesterase activity. Having a rare cholinesterase genotype is just one possible cause of low activity. During pregnancy activity can fall $20-30 \%$ partly due to hemodilution and partly to reduced synthesis by liver, with activity being lowest on the 3 rd day after delivery. The newborn has about $50 \%$ of normal activity and reaches normal levels at 3-4 years of age. Diseases which affect synthesis of cholinesterase by liver, for example, acute hepatitis, liver metastasis, and liver cirrhosis, often reduce activity to $50 \%$. Activity can be low in cholecystitis, renal disease, myocardial infarction, muscular dystrophy, congenital myotonia, dermatomyositis, hyperpyrexia, rheumatic fever, typhus, tetanus, tuberculosis, acute infections, carcinomas, chronic debilitating diseases, chronic anemias, epilepsy, myxodema and uremia. Malignant tumors of the gastrointestinal tract and lung appear to depress cholinesterase more than tumors located elsewhere, and activity can fall below $25 \%$ of normal. In burn patients activity can fall to $20 \%$ of normal. Surgical shock, X-ray therapy, and kidney dialysis can reduce activity. Organophosphates, such as in pesticides (paraoxon) and certain anticancer drugs (cyclophosphamide, Endoxan, Thio-tepa) irreversibly inhibit cholinesterase. Patients treated with Endoxan or Thio-tepa have $35-70 \%$ of normal activity. Echothiopate eye drops used one drop in each eye twice a day can reduce activity to nearly zero. After discontinuation of treatment. with organophosphate drugs it can take two weeks to regain $70 \%$ of normal activity and 6-8 weeks to regain full activity, because the cholinesterase must be newly synthesized by the liver. Reversible cholinesterase inhibitors that depress activity transiently are bambuterol (Fisher et al., 1988), edrophonium, neostigmine, and pyridostigmine. Other drugs that depress activity are monoamine oxidase inhibitors, contraceptive pills, propanidid, chlorpromazine, pancuronium, and local anesthetics. Activity can be severely depressed in kwashiorkor and malnutrition.

What level of usual cholinesterase activity is considered low for purposes of predicting succinylcholine apnea? Activities of $154-543 \mu \mathrm{mol}$ benzoylcholine per min per liter of plasma were found in 14 succinylcholine-sensitive patients of the usual genotype. The normal activity range is $690-1560 \mathrm{U} / \mathrm{L}$. In this group of patients the dose of succinylcholine ranged from $50-250 \mathrm{mg}$ and the duration of apnea was 15-240 min (Viby-Mogensen and Hanel, 1978).

\subsection{Phenotyping Procedures}

\subsubsection{Phenotyping by Dibucaine Number}

Problems with succinylcholine are rare, occurring in 1 patient per 100 Europeans and Americans. Therefore patients are not routinely screened for cholinesterase activity and genotype. Testing is confined to patients who have a history of succinylcholine apnea and to relatives of such patients.

It is not possible to discriminate between the various cholinesterase genotypes by activity tests alone, as shown by Fig. 4. Kalow developed a simple method for determining who was a carrier of atypical cholinesterase. He introduced the 'Dibucaine
Number' (DN), which is the percent inhibition of hydrolysis of substrate in the presence of $10 \mu \mathrm{M}$ dibucaine (Kalow and Genest, 1957). Figure 5 illustrates the differential inhibition achieved by dibucaine. Usual cholinesterase is very sensitive to dibucaine which inhibits $80 \%$ of its activity; UU has a dibucaine number of 80 (range 77-83). Atypical cholinesterase is resistant to dibucaine being inhibited only $20 \%$ (DN 20 ; range $8-28$ ), and the heterozygote has intermediate sensitivity so that $60 \%$ of its activity is inhibited (DN 60; range 48-69) (Whittaker, 1986). Though other inhibitors also discriminate between usual and atypical genotypes, dibucaine was chosen because it is readily available, is stable in solution, and inhibits immediately. Determination of dibucaine number is still the best, most accurate, simplest, and most widely used method for cholinesterase phenotyping. The idea of discriminating by means of differential sensitivity to an inhibitor has been used to identify new genetic variants. Inhibitors including sodium fluoride, RO 2-0683 from HoffmannLa Roche = the dimethylcarbamate of (2-hydroxy-5phenylbenzyl)-trimethylammonium, sodium chloride, succinylcholine, butanol, and urea are used to identify fluoride, $\mathbf{H}, \mathrm{J}$, and $\mathrm{K}$ variants. The substrate preferred by many laboratories is benzoylcholine because benzoylcholine is specifically hydrolyzed by serum cholinesterase and not by red cell acetylcholinesterase, is stable in solution, and has simple kinetics. Hospital laboratories often prefer butyrylthiocholine or propionylthiocholine because these substrates are suitable for single time point assays on an automated analyzer. Dibucaine numbers can be measured with any of these substrates, though the reference values for interpreting the meaning of a measured dibucaine number will differ depending on the substrate, temperature and buffer.

\subsubsection{Importance of Nerve Stimulator}

The anesthesiologist can exclude cases of respiratory insufficiency that have no connection with cholinesterase levels and genotypes by using a nerve stimulator. If no neuromuscular block is observed with the nerve stimulator then succinylcholine is not involved. However, the presence of a phase II neuromuscular block following a single normal dose of succinylcholine indicates an abnormal cholinesterase genotype (Viby-Mogensen, 1983). This simple test in the operating room eliminates $15-20 \%$ of cases from further consideration. The nerve stimulator can give a preliminary idea of the cholinesterase phenotype. By using the nerve stimulator and observing time to spontaneous recovery, Viby-Mogensen can discriminate between patients with genotype AF or FS, and patients with AA, AS or SS genotypes.

\subsubsection{Polymerase Chain Reaction followed by DNA sequencing}

This procedure was first used for cholinesterase by McGuire et al. (1989). It is based on knowledge of the nucleotide sequence of human serum cholinesterase including the complete coding sequence as well as intron sequences near exon/intron boundaries. The DNA sequence is required to design oligonucleotide 

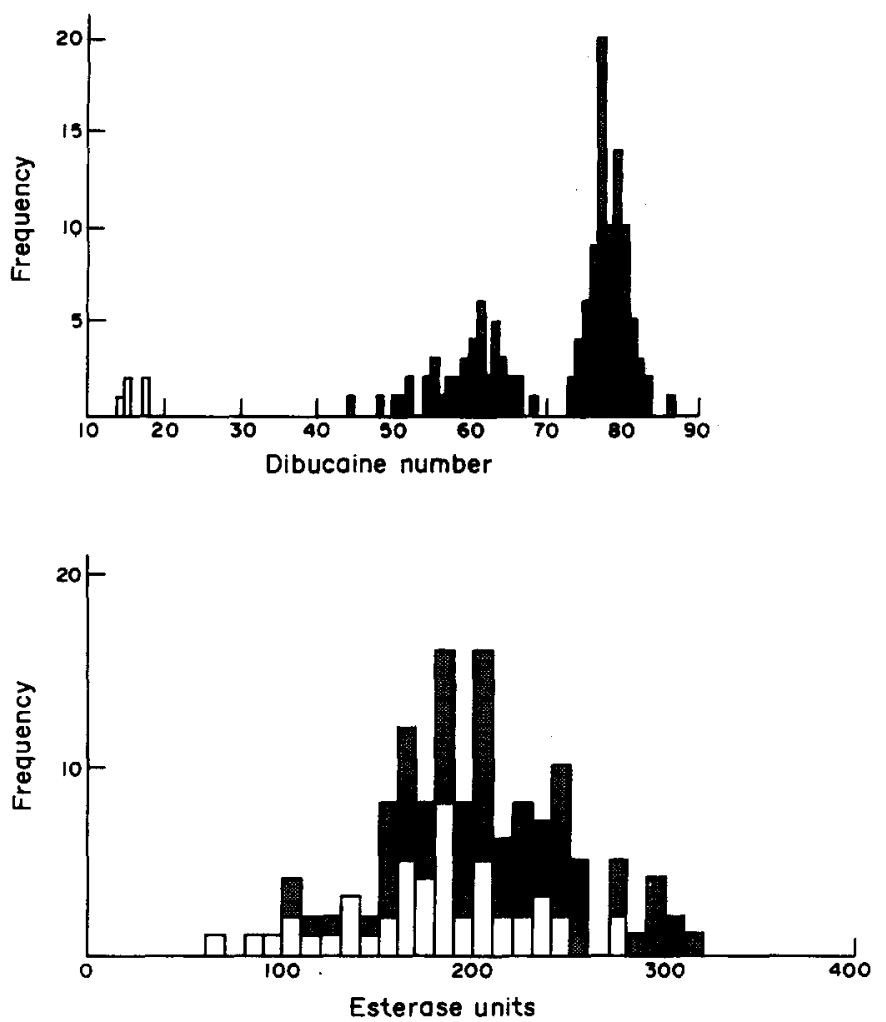

FIG. 4. Dibucaine number separates AA, UA, and UU genotypes into three groups, in contrast to activity measurement which gives only one group. The frequency distribution of dibucaine numbers among 135 members of seven unrelated families is shown in the top graph. The same sera were tested for activity and results are shown in the bottom graph. The black columns show esterase activity of sera with dibucaine number below 70 (Kalow and Staron, 1957). Reprinted with the permission of the authors and the copyright holder, The National Research Council of Canada, Ottawa.

primers that match the cholinesterase gene at the beginning and end of the region to be examined. The oligonucleotides are used to prime amplification of the cholinesterase gene.

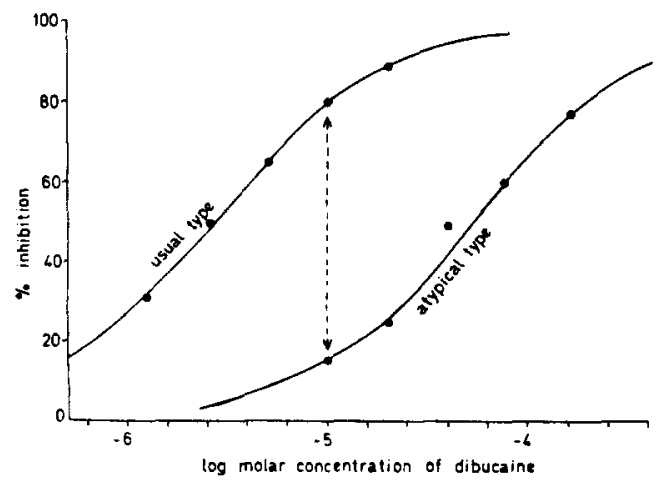

FiG. 5. Percentage inhibition of activity of usual and atypical cholinesterases by different concentrations of dibucaine. Optimal discrimination between usual and atypical cholinesterases was obtained with $10^{-5} \mathrm{M}$ dibucaine. Activity was measured spectrophotometrically with benzoylcholine as substrate (Kalow and Genest, 1957). Reprinted with the permission of the authors and the copyright holder, the National Research Council of Canada, Ottawa.
We usually obtain $20 \mathrm{ml}$ of whole blood in citrate anticoagulant from each donor. DNA is prepared from the white cells in the buffy coat. A small aliquot of this genomic DNA is amplified by means of the polymerase chain reaction, yielding millions of copies of a segment of the cholinesterase DNA. The amplified, double-stranded cholinesterase DNA is sequenced by a modification of the Sanger dideoxy sequencing procedure. An example of sequencing results is in Fig. 6. Best results are obtained when the amplified fragment is short, $200-400$ base pairs. Since the cholinesterase mRNA is 2.4 kilobase pairs in length, the procedure has to be repeated about 10 times to obtain the complete sequence of a new variant. However, genotyping is much simpler once the nucleotide alterations are known, because amplification and sequencing can focus on just one region. Kalow's phenotyping method remains an essential prerequisite before launching into a week-long project for determination of DNA sequence. To date the correlation between dibucaine number and DNA sequencing results has been perfect for the atypical locus.

\subsection{Drugs Hydrolyzed by Cholinesterase}

A list of ester drugs hydrolyzed by cholinesterase is in Table $2 . K_{\mathrm{m}}$ values for hydrolysis by both usual and atypical cholinesterases are in Table 3. The $K_{\mathrm{m}}$ 

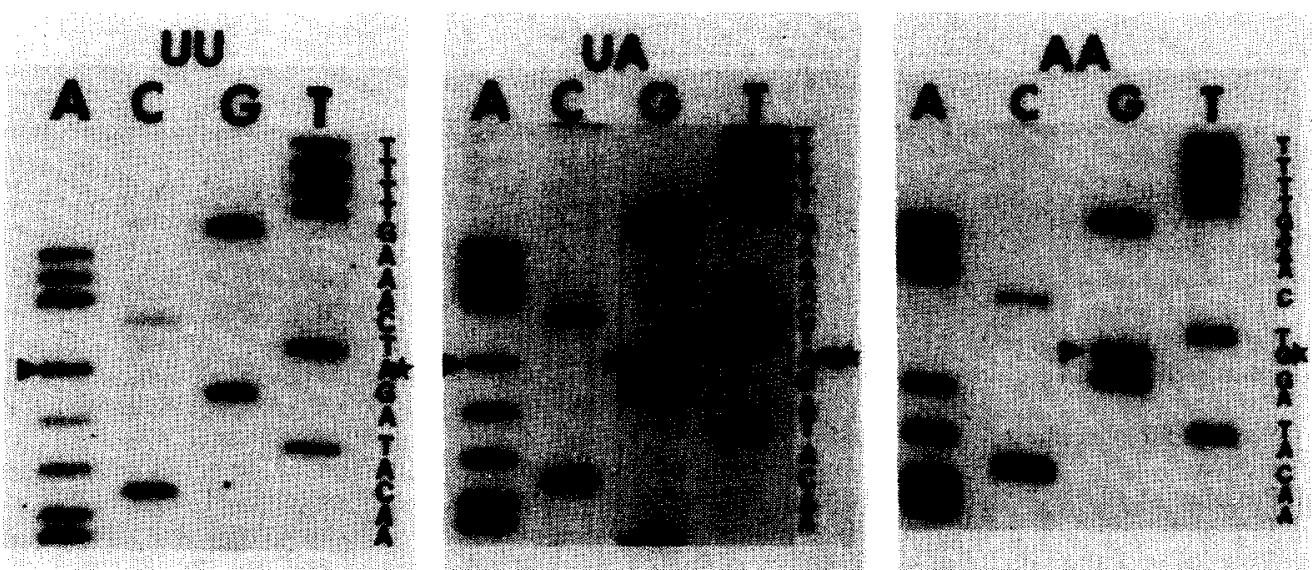

FIG. 6. DNA sequences of usual (UU), heterozygous (UA), and atypical (AA) cholinesterases showing the nucleotide substitution in atypical cholinesterase. Total genomic DNA from three individuals was amplified by the polymerase chain reaction with oligonucleotides corresponding to the coding region of the cholinesterase gene. Both strands of the double-stranded, amplified DNA were sequenced simultaneously. The sequences are identical except for the nucleotide marked with a star. Codon 70 is GAT in UU, GAT and GGT in UA, and GGT in AA (McGuire et al., 1989).

values show that atypical has a lower affinity for these compounds and therefore slower hydrolysis at clinical doses. Succinylcholine and cocaine are not hydrolyzed by atypical cholinesterase at doses found in circulating blood (Goedde et al., 1968; Stewart et al., 1977), though they are hydrolyzed by usual cholinesterase. It is likely that most of the drug esters in Table 2 are poorer substrates for atypical cholinesterase than for usual cholinesterase when measurements are made with low drug concentrations. However, the extrapolated rate obtained from a Lineweaver-Burk plot, that is, the maximum rate of hydrolysis at saturating substrate concentration, has the same value for both atypical and usual cholinesterases. This extrapolated maximum hydrolysis rate is shown in Table 2 as turnover number. These values indicate that the best substrates are aspirin, meprylcaine, isobucaine and chloroprocaine and the poorest are cocaine and aprophen. All drugs in
Table 2 are hydrolyzed slowly compared to esters commonly used as substrates, namely benzoylcholine and butyrylthiocholine.

Four case reports suggest that procaine and chloroprocaine may have prolonged or toxic effects in people with atypical or silent cholinesterase (Downs, 1966; Zsigmond and Eilderton, 1968; Doenicke et al., 1963; Kuhnert et al., 1982). Procaine applied to the skin of a person with silent cholinesterase had a prolonged effect lasting more than $160 \mathrm{~min}$, compared to the normal $25 \mathrm{~min}$ (Doenicke et al., 1963). Chloroprocaine injected for epidural anesthesia had an abnormally long duration of approximately $3 \mathrm{hr}$ in a patient with atypical cholinesterase; normally the block lasts 45-60 min (Kuhnert et al., 1982). However, Raj et al. (1977) saw no increase in the duration of block in an atypical cholinesterase patient who received chloroprocaine. In clinical practice today procaine is rarely used and therefore problems are

TABle 2. Drugs Hydrolyzed by Human Serum Cholinesterase

\begin{tabular}{|c|c|c|c|c|}
\hline Drug ester & Use & Effect of ChE & $\begin{array}{l}\text { Turnover } \\
\text { number }\end{array}$ & Reference \\
\hline Succinylcholine & $\begin{array}{l}\text { Depolarizing muscle } \\
\text { relaxant }\end{array}$ & Inactivate & 300 & Goedde et al., 1968 \\
\hline Procaine & Local anesthetic & Inactivate & 255 & Valentino et al., 1981 \\
\hline 2-Chloroprocaine & Local anesthetic & Inactivate & 1,200 & Foldes et al., 1965 \\
\hline Meprylcaine & Local anesthetic & Inactivate & 2,750 & Foldes et al., 1965 \\
\hline Isobucaine & Local anesthetic & Inactivate & 2,250 & Foldes et al., 1965 \\
\hline Tetracaine & Local anesthetic & Inactivate & 74 & Valentino et al., 1981 \\
\hline Aspirin & Analgesic & Inactivate & 7,200 & Valentino et al., 1981 \\
\hline Heroin & Narcotic & $\begin{array}{l}\text { Convert to } \\
\text { 6-acetyl morphine }\end{array}$ & 500 & Lockridge et al., 1980 \\
\hline Cocaine & $\begin{array}{l}\text { CNS stimulant and } \\
\text { Local anesthetic }\end{array}$ & & 0.4 & Stewart et al., 1977 \\
\hline Methylprednisolone acetate & Anti-inflammatory agent & Activate & 25 & Myers et al., 1982 \\
\hline Aprophen & $\begin{array}{l}\text { Antispasmodic and } \\
\text { anticonvulsant }\end{array}$ & Inactivate & 0.12 & Rush et al., 1985 \\
\hline Mivacurium & $\begin{array}{l}\text { Nondepolarizing } \\
\text { muscle relaxant }\end{array}$ & Inactivate & & Savarese et al., 1988 \\
\hline Bambuterol & Bronchodilator & Activate & & Tunek and Svensson, 1988 \\
\hline
\end{tabular}

Turnover is the maximal velocity at saturating substrate concentration expressed as mol hydrolyzed per min per mol active site. Turnover numbers for succinylcholine, chloroprocaine, meprylcaine, isobucaine, and cocaine are based on data in the references and do not appear as such in the references. 
TABLE 3. $\mathrm{K}_{m}$ Values and Turnover Numbers for Substrates of Usual and Atypical Cholinesterase

\begin{tabular}{|c|c|c|c|c|}
\hline & \multicolumn{2}{|c|}{$K_{\mathrm{m}}(\mathrm{mM})$} & \multirow{2}{*}{$\begin{array}{l}\text { Turnover } \\
\text { number }\end{array}$} & \multirow[b]{2}{*}{ Reference } \\
\hline & Usual " & Átypical & & \\
\hline \multicolumn{5}{|l|}{ Positively charged } \\
\hline Acetylcholine Cl & 1.4 & 9.0 & 33,200 & Davies et al., 1960 \\
\hline Propionylcholine I & 0.97 & 3.1 & 55,000 & Davies et al., 1960 \\
\hline Butyrylcholine I & 0.91 & 1.7 & 80,000 & Davies et al., 1960 \\
\hline Pentanoylcholine I & 0.72 & 1.5 & 63,000 & Davies et al., 1960 \\
\hline Hexanoylcholine I & 0.57 & 0.82 & 36,000 & Davies et al., 1960 \\
\hline Heptanoylcholine I & 0.38 & 1.11 & 35,000 & Davies et al., 1960 \\
\hline Benzoylcholine $\mathrm{Cl}$ & 0.004 & 0.022 & 15,000 & $\begin{array}{l}\text { Davies et al., 1960; } \\
\text { Lockridge and La Du, } 1978\end{array}$ \\
\hline Succinyldithiocholine & 0.035 & 1.08 & 600 & Hersh et al., 1974 \\
\hline Heroin & 0.11 & 0.45 & 500 & Lockridge et al., 1980 \\
\hline Procaine & 0.0066 & 0.10 & 255 & Valentino et al., 1981 \\
\hline Tetracaine & 0.00014 & 0.008 & 74 & Valentino et al., 1981 \\
\hline $\begin{array}{l}N \text {-methyl-(7-dimethyl } \\
\text { carbamoxy)quinolinium I }\end{array}$ & 0.00008 & 0.002 & 0.0025 & Lockridge and La Du, 1978 \\
\hline \multicolumn{5}{|l|}{ Neutral } \\
\hline$o$-Nitrophenylbutyrate & 0.33 & 0.4 & 48,000 & Valentino et al., 1981 \\
\hline$\alpha$-Naphthylacetate & 1.0 & 0.37 & 36,000 & Valentino et al., 1981 \\
\hline $\begin{array}{l}\alpha \text {-Naphthylacetate }+ \\
20 \mathrm{mM} \mathrm{CaCl}\end{array}$ & 0.4 & 0.37 & 36,000 & Valentino et al. 1981 \\
\hline Methylprednisolone & & & & \\
\hline acetate & 1.0 & - & 25 & Myers et al., 1982 \\
\hline $\begin{array}{l}\text { Negatively charged } \\
\text { aspirin }+50 \mathrm{mM} \mathrm{CaCl}\end{array}$ & 4.2 & 16 & 7.200 & Valentino et al 1981 \\
\hline
\end{tabular}

Turnover number is defined as the maximal velocity at saturating substrate concentration expressed as mol substrate hydrolyzed per min per mol active site. Turnover number is the same for usual and atypical cholinesterases. $K_{\mathrm{m}}$ and $V_{\max }$ were determined at $25^{\circ} \mathrm{C}$ in pH 7.4 buffer, except for succinylcholine which was at $30^{\circ} \mathrm{C}$. Values in Davies et al. (1960) and Hersh et al. (1974) were converted to turnover numbers (TN) using the relationship $V_{\max }$ ester $/ V_{\max }$ benzoylcholine $=\mathrm{TN}$ ester $/ \mathrm{TN}$ benzoylcholine.

infrequent. In the rare instances when dentists still use procaine (novocaine) as a local anesthetic they inject procaine intramuscularly along with a vasoconstrictor. This mode of application makes hydrolysis unimportant and therefore problems are not expected with rare cholinesterase variants.

It is possible but as yet undocumented that people with atypical cholinesterase might be unusually sensitive to heroin. This possibility arose when it was found that heroin was hydrolyzed more slowly by atypical cholinesterase due to a decreased affinity. Serum from a person identified as having silent cholinesterase did not hydrolyze heroin at all (Lockridge et al., 1980). The product of heroin hydrolysis by cholinesterase is 6-acetylmorphine. Heroin and 6-acetylmorphine penetrate the blood-- brain barrier and are slowly hydrolyzed to the pharmacologically active agent, morphine, by enzymes in the brain. Cholinesterase does not produce morphine. Cholinesterase is the only enzyme in human serum that hydrolyzes heroin, though enzymes in red blood cells account for $50-70 \%$ of the heroin hydrolysis observed in whole blood.

No association has been made between atypical cholinesterase and problems with aspirin or tetracaine even though these compounds are hydrolyzed more slowly by atypical cholinesterase (Valentino et al., 1981). Methylprednisolone acetate is converted to its active form by hydrolysis of the ester bond. Cholinesterase in serum accounts for $25 \%$ of the hydrolysis observed in vivo. This makes it unlikely that a person with atypical cholinesterase would have an abnormal response to methylprednisolone acetate (Myers et al., 1982).
Mivacurium chloride is a new short-acting nondepolarizing, neuromuscular blocking drug undergoing clinical trials (Savarese et al., 1988). The diester is hydrolyzed by cholinesterase at about the same rate as succinylcholine. In individuals who have atypical cholinesterase its duration of action may be prolonged though this has not yet been tested.

Bambuterol is a new dicarbamate prodrug especially designed to inhibit cholinesterase, thus allowing slow release of the active compound, terbutaline. The slow release may allow a person to take this antiasthma drug just once a day. The potency of bambuterol is similar to that of the dimethylcarbamate R02-0683 and of organophosphate esters, all having $I_{50}$ of $10^{-8}$ to $10^{-9} \mathrm{M}$, with the difference that carbamate-inhibited cholinesterase regains full activity in $24 \mathrm{hr}$, whereas organophosphate-inhibited cholinesterase is irreversibly inhibited. Bambuterol taken orally $10 \mathrm{hr}$ before surgery had the effect of prolonging succinylcholine-induced paralysis in humans (Fisher et al., 1988). The effect of bambuterol in atypical cholinesterase patients has not yet been studied, but it is known that atypical plasma hydrolyzes bambuterol at a slower rate (Tunek et al., 1988). Another special feature of bambuterol is that it does not inhibit acetylcholinesterase at therapeutic doses. This selective inhibition of cholinesterase is important to the patient because it avoids toxic effects. Another consequence is that bambuterol di criminates between cholinesterase and acetylcholinesterase more selectively than the classic iso-OMPA and BW284C51 (Tunek and Svensson, 1988). 


\subsection{Other Esterases Involved IN DRUg METABOLISM}

Several human enzymes may be involved in the hydrolysis of the drug esters in Table 2 . Red blood cells contain at least three esterases: acetylcholinesterase, carbonic anhydrase and esterase D. Monocytes and lymphocytes contain acid esterase, which is also called alpha-naphthyl acetate esterase. Serum and plasma contain cholinesterase and arylesterase/paraoxonase. Succinylcholine is known to be hydrolyzed exclusively by cholinesterase in serum and not by acetylcholinesterase in red blood cells. However, heroin is hydrolyzed both by serum cholinesterase and by other esterases in whole blood, though not by arylesterase/paraoxonase in plasma. Aprophen is hydrolyzed by serum cholinesterase and by liver carboxylesterases, but not by acetylcholinesterase. Genetic variants are known not only for cholinesterase but also for arylesterase/ paraoxonase (Eckerson et al., 1983b), carbonic anhydrase (Venta et al., 1987), and esterase D (Lee and Lee, 1986). No genetic variants are known for human acetylcholinesterase.

\section{THE USUAL CHOLINESTERASE PROTEIN}

To understand the genetic variants we need to establish the properties of the usual cholinesterase protein. The following summarizes recent structural results for usual cholinesterase.

\subsection{Purification of Usual Cholinesterase Protein}

Cholinesterase is routinely purified in our laboratory from $10 \mathrm{~L}$ of outdated human plasma by a three-step procedure. This scaled-up procedure has not been previously published though we gave a brief description when we introduced the procainamide affinity gel (Lockridge and $\mathrm{La} \mathrm{Du}, 1978$; Lockridge et al., 1979). Figure 7 is an example of purification of usual cholinesterase. Details of the purification are in the figure legend. The yield from $10 \mathrm{~L}$ is $8-12 \mathrm{mg}$ of electrophoretically pure cholinesterase.

\subsection{SPECIFIC ACTIVITY OF ELECTROPHORETICALLY Pure Cholinesterase}

There is wide variety in the literature regarding the specific activity of human serum cholinesterase preparations that are considered pure. The following specific activity values are the highest obtained by us, and are higher than those reported by other laboratories. For the substrate benzoylcholine, the specific activity is $200 \mu \mathrm{mol}$ benzoylcholine hydrolyzed per minute per mg protein; for the substrate butyrylthiocholine, the specific activity is $700 \mu \mathrm{mol}$ butyrylthiocholine hydrolyzed per minute per $\mathrm{mg}$ protein.

Specific activity is measured using either benzoylcholine or butyrylthiocholine. Benzoylcholine activity is measured with $0.05 \mathrm{~mm}$ benzoylcholine in $0.067 \mathrm{M}$
$\mathrm{Na} / \mathrm{K}$ phosphate buffer $\mathrm{pH} 7.4$, at $25^{\circ} \mathrm{C}$ (Kalow and Lindsay, 1955). The buffer contains $75.84 \mathrm{~g}$ of anhydrous $\mathrm{Na}_{2} \mathrm{HPO}_{4}$ and $18.156 \mathrm{~g}$ of anhydrous $\mathrm{KH}_{2} \mathrm{PO}_{4}$ per $10 \mathrm{~L}$ of water, and is sterilized by either filtration or autoclaving. The reason for sterilizing the buffer is to avoid degradation of benzoylcholine by microbes. Activity is measured at $240 \mathrm{~nm}$ using an extinction coefficient of $6700 \mathrm{M}^{-1} \mathrm{~cm}^{-1}$ for the difference in absorbance between substrate and product. Hydrolysis of butyrylthiocholine is measured using the Ellman assay modified for cholinesterase (Ralston et al., 1983). The reagent concentrations are $1.0 \mathrm{~mm}$ butyrylthiocholine in $0.1 \mathrm{M}$ sodium phosphate buffer pH 8.0, and $0.3 \mathrm{~mm}$ DTNB, at $25^{\circ} \mathrm{C}$. The extinction coefficient for the yellow product is $13,600 \mathrm{M}^{-1} \mathrm{~cm}^{-1}$ at $412 \mathrm{~nm}$. One unit is defined as the amount of enzyme that hydrolyzes $1 \mu \mathrm{mol}$ substrate per min. Protein concentration is measured by absorbance at $280 \mathrm{~nm}$, where an absorbance of 1.8 corresponds to a concentration of $1 \mathrm{mg} / \mathrm{ml}$. Preparations having a specific activity of 200 units/mg with benzoylcholine, and a specific activity of 700 units $/ \mathrm{mg}$ with butyrylthiocholine appear pure on polyacrylamide gel electrophoresis, have an amino acid composition that agrees with the composition calculated from the amino acid sequence, and have a single $\mathrm{N}$-terminal sequence. These highly purified preparations still contain trace amounts of peptidase contaminants (see below).

We prefer benzoylcholine over butyrylthiocholine for assaying serum samples and for studies in which activity is measured at a range of substrate concentrations (for example, $K_{\mathrm{m}}$ and $K_{\mathrm{i}}$ determinations) for 2 reasons. (1) Benzoylcholine is specifically hydrolyzed by cholinesterase and not by acetylcholinesterase; butyrylthiocholine on the other hand is hydrolyzed by both enzymes and there can be some activity from acetylcholinesterase released from red blood cells. (2) Benzoylcholine has simple kinetics so that a Lineweaver-Burk plot for the range $0.013-0.10 \mathrm{mM}$ benzoylcholine gives a straight line; in contrast, butyrylthiocholine has complicated kinetics even with highly purified cholinesterase. A Lineweaver-Burk plot gives a curve for the range $0.6-10 \mathrm{~mm}$ butyrylthiocholine.

\subsection{Molecular Weight}

The 574 amino acids in the subunit have a weight of 65,092 (Lockridge et al., 1987b). The nine carbohydrate chains in each subunit contribute $23.9 \%$ of the final weight so that the total weight of the subunit is 85,534 . The molecule is a tetramer of 4 identical subunits and thus the enzyme molecular weight is 342,136 . This value is approximate because the weight of carbohydrate is not exact. Sizes determined by other methods are in agreement with the size obtained by amino acid sequencing. Molecular weights of the monomer and dimer are 90,000 and 180,000 respectively, on SDS gel electrophoresis. The subunit weight is 85,000 on ultracentrifugation, 81,000 and 86,000 on Sephadex gel filtration, and 100,000 when titrated with DFP or paraoxon. The molecular weight of the tetramer is 348,000 by ultracentrifugation. 


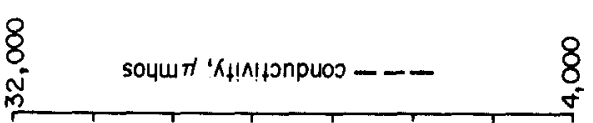

jw/st!un 0-0-0
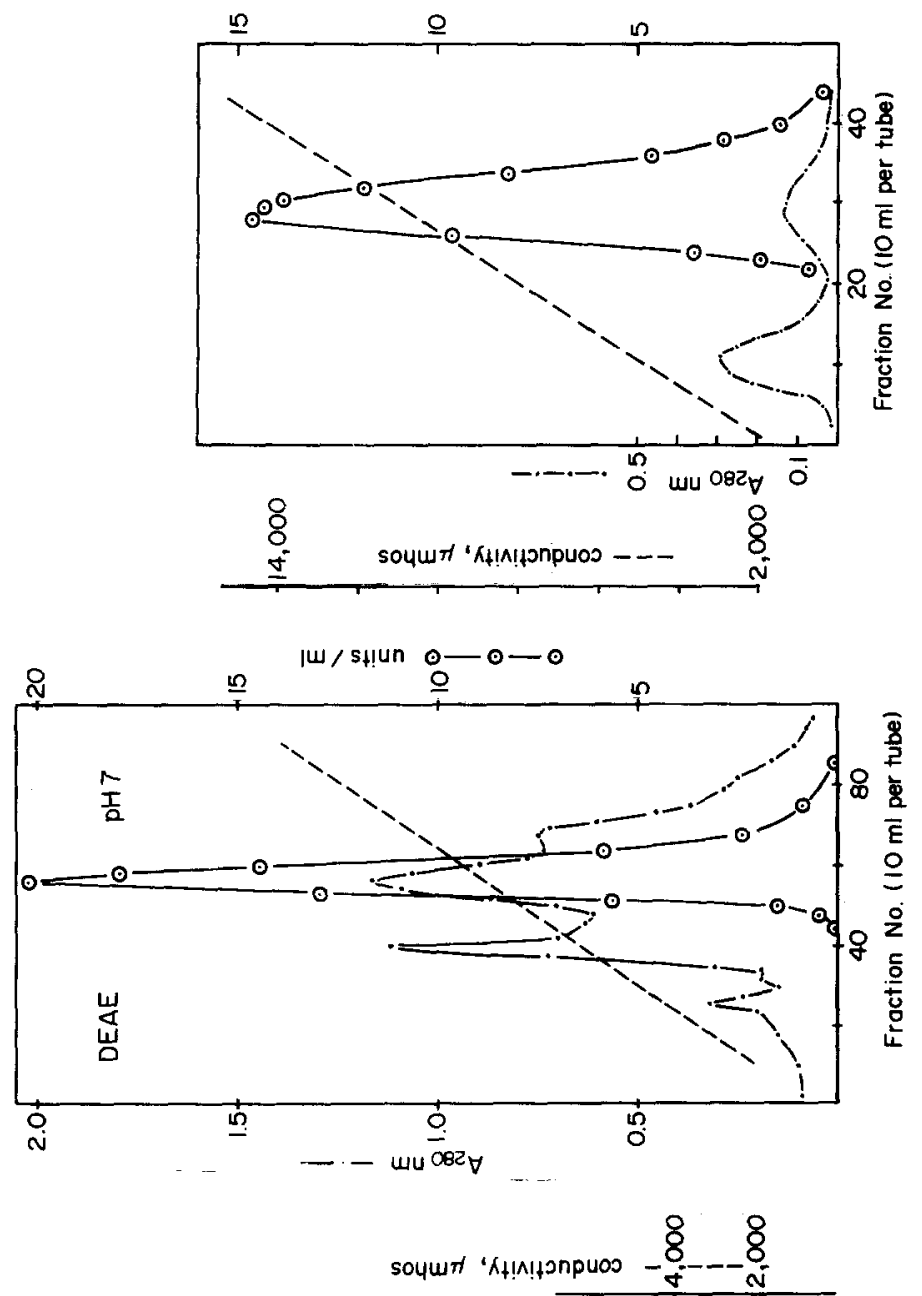

jw/st!un $0-0-0$

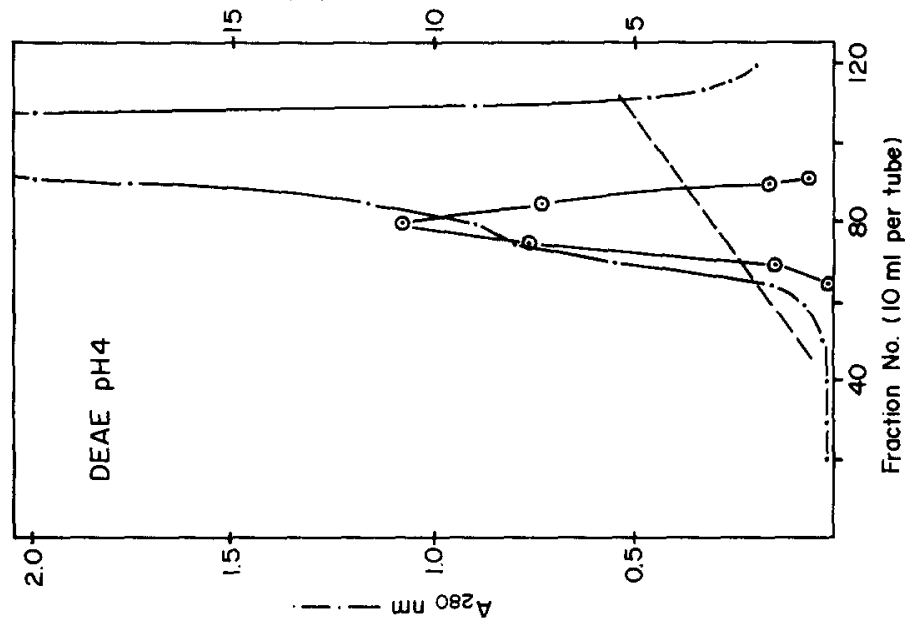

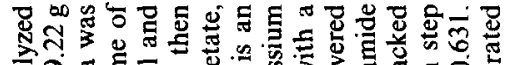

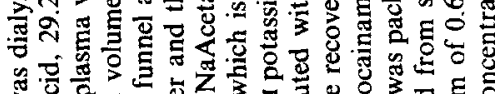

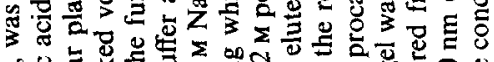

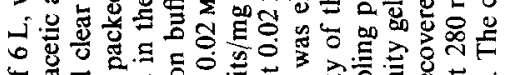

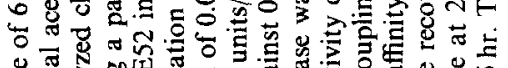

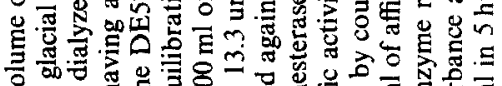

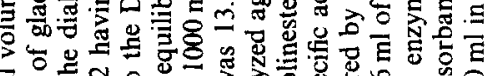

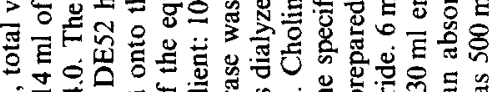

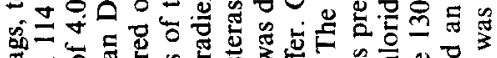

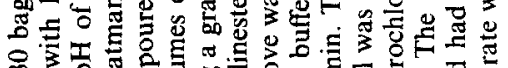

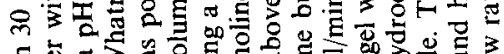

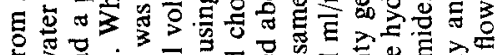

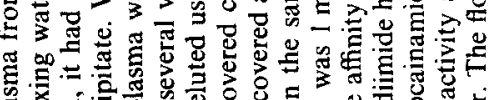

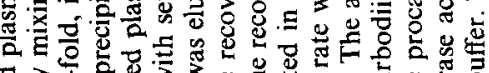

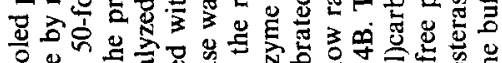

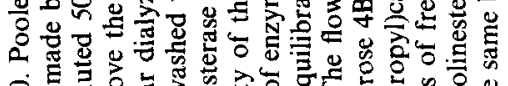
० 行

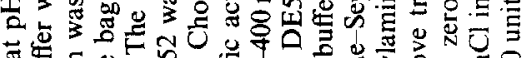

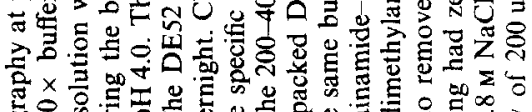

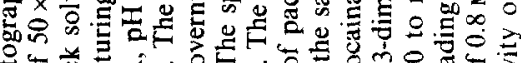

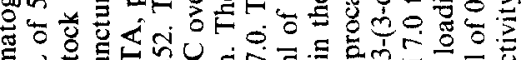

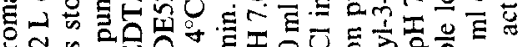

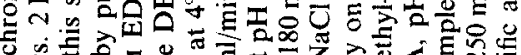

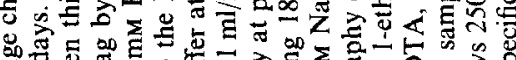

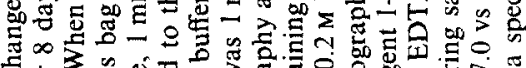

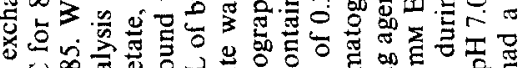

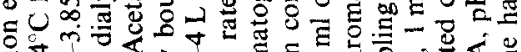

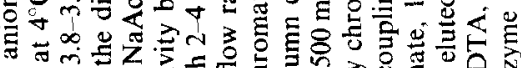

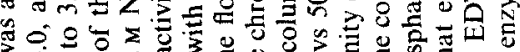

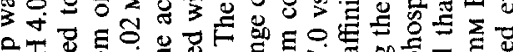

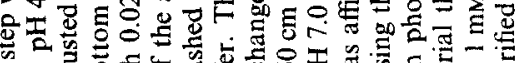

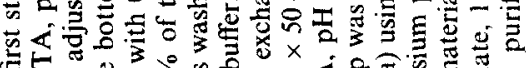

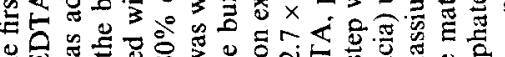

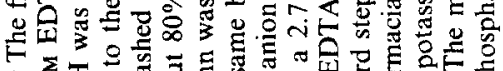

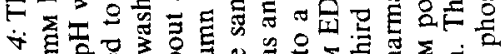

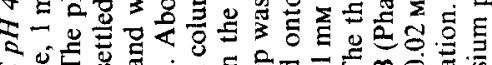

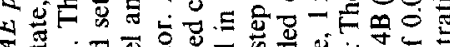

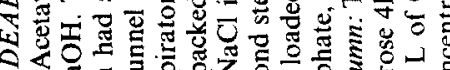

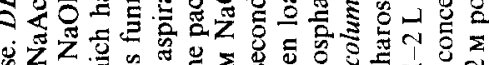

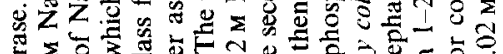
岁资

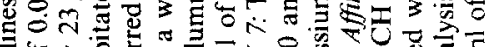

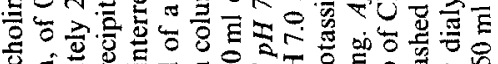

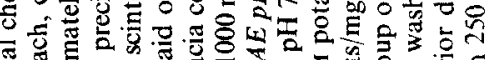

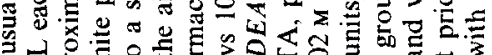
응

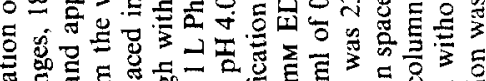

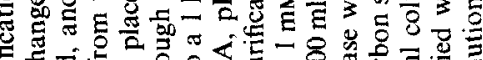

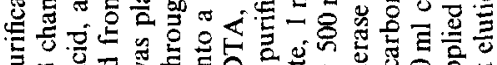

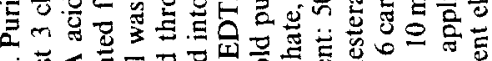

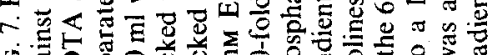

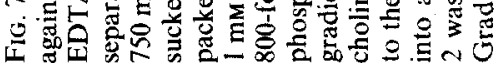




\subsection{Protease Contamination}

Unidentified blood proteases copurify with serum cholinesterase in the early steps of the purification. However, protease contaminants are absent in cholinesterase that is electrophoretically homogeneous. We observed the effects of these protease contaminants during amino acid sequencing. When a $65-75 \%$ pure preparation (130-150 units $/ \mathrm{mg}$ ) was used for amino acid sequencing, peptides with unexpected termini were obtained. This problem was absent when more highly purified preparations were used.

There is other evidence of protease contamination in partially purified cholinesterase. Such preparations are unstable in solution at $4^{\circ} \mathrm{C}$. In contrast, our purest preparations are stable for years at $4^{\circ} \mathrm{C}$ in $\mathrm{pH} 7$ phosphate buffer containing $0.1 \mathrm{mM}$ EDTA. Another way of seeing the effects of the protease contaminants is by polyacrylamide gel electrophoresis followed by staining for cholinesterase activity; over a period of months of storage the enzyme, which is normally a tetramer, partially degrades to the smaller $\mathrm{C} 1$ and $\mathrm{C} 3$ 'isozymes'. The same result can be obtained in a few hours by adding trypsin (Lockridge and $\mathrm{La} \mathrm{Du}$, 1982). The effects of limited proteolysis may not show up in activity assays, because the partially proteolyzed molecule can be fully active. The proteolysis may not be evident on sucrose gradient centrifugation since the great majority of the partially proteolyzed cholinesterase is still a tetramer

The most sensitive way to find out whether a purified cholinesterase preparation has undergone some proteolysis is to subject the cholinesterase to SDS gel electrophoresis in the absence of added mercaptoethanol or dithiothreitol. Under these conditions the native tetramer is dissociated into dimers. Any material having a monomer size of 85,000 daltons is the result of proteolysis. The relative amount of monomer to dimer gives an estimate of the extent of proteolysis. If a single dimer band of 170,000 daltons is obtained, then the cholinesterase is intact.

Commercially purified human cholinesterase is often only partially pure and is highly likely to contain proteolytic nicks. Studies using commercial cholinesterase should keep in mind that physical parameters may be altered and complicated by the proteolytic nicking. For example, heat stability may be reduced to well below the normal half-life of $54 \mathrm{~min}$ at $55^{\circ} \mathrm{C}$. Cholase from Behringwerke $\mathrm{AG}$ is $5.5 \%$ pure. This is the preparation used successfully by the Danish Cholinesterase Research Unit to reverse succinylcholine apnea (Viby-Mogensen, 1981b).

\subsection{Peptidase Contamination}

Our most highly purified cholinesterase preparation had the ability to hydrolyze the peptide hormone, Substance P (Lockridge, 1982). The rate of hydrolysis was very slow requiring $0.2 \mathrm{mg}$ of cholinesterase over a period of $48 \mathrm{hr}$ to hydrolyze $0.2 \mathrm{mg}$ of Substance P. Several laboratories agreed that highly purified cholinesterase was capable of hydrolyzing Substance P. However, the interpretation of Nausch and Heymann (1985) and Kaemmer et al. (1986) was that the enzyme catalyzing this hydrolysis was a contaminant, identified as dipeptidyl peptidase IV. The evidence supporting this interpretation was that the ester hydrolyzing activity of cholinesterase was completely inhibited by physostigmine (eserine) without affecting Substance P degrading activity. Conversely, an inhibitor of dipeptidyl peptidase IV inhibited peptidase activity more than esterase activity. In addition, Chatonnet and Masson (1985) showed that two different DFP sensitive sites were responsible for hydrolysis of the ester and the peptide. The peptidase contaminant cannot be seen on SDS gels stained for protein or by measuring radioactivity from bound DFP in gel slices because the contaminant comigrates with cholinesterase (Chatonnet and Masson, 1986). In separate studies, Boopathy and Balasubramanian (1987) reported a peptide cleavage specificity and inhibition sensitivity in cholinesterase preparations that was not characteristic of dipeptidylamino peptidase IV, but could be due to a different peptidase. The amount of peptidase contaminant is probably no greater than $1-3 \%$ by weight.

Despite the above arguments that peptidase activity is from a contaminant, the issue is not yet settled. The possibility that cholinesterase has a second activity and even a second active site has not been ruled out. The idea of a second active site is supported by studies with acetylcholinesterase where numerous reports suggest that acetylcholinesterase from various sources including electric eel (Small et al., 1987), sheep basal ganglia (Majumdar et al., 1988), and fetal calf serum (Small, 1988) has peptidase activity and that its function in noncholinergic tissues is to process neuropeptides. Fasciculin is a 61 amino acid peptide from the venom of green mamba snake. It is a powerful inhibitor of both acetylcholinesterase and cholinesterase, leaving no doubt that these enzymes have the ability to bind a peptide (Mbugua and Karlsson, 1985).

\subsection{SDS GEL. ELECTOPHORESIS}

On SDS gel electrophoresis cholinesterase has a single dimeric band of 170,000-180,000 daltons in the absence of mercaptoethanol and dithiothreitol. In the presence of reducing agent, there are two bands: a major band at 85,000-90,000 daltons and a minor band at 170,000-180,000 daltons (Lockridge et al., 1979). The 85,000 band is the monomeric subunit, while the 170,000 band is residual unreduced dimer. If a preparation shows both bands in the absence of reducing agent, then the cholinesterase has undergone partial proteolysis resulting in removal of a small peptide from the $\mathrm{C}$-terminal containing the interchain disulfide bond (Lockridge and $\mathrm{La} \mathrm{Du}$, 1982). The partially proteolysed monomer has the same apparent molecular weight as intact monomer. The interchain disulfide bond is located 4 amino acids from the end of the subunit (Lockridge et al., 1987a). Therefore proteolytic removal of these 4 amino acids does not significantly alter the subunit weight. Boiling the enzyme for $10 \mathrm{~min}$ or longer in the loading buffer for SDS gels ( $5 \%$ glycerol, $1 \%$ SDS) creates artifacts by degrading the dimer into several small bands including a heavy monomer sized band. 
Cholinesterase bands are broad on SDS gels because of the high carbohydrate content of $23.9 \%$ by weight. This prevents detection of small changes in size, and prevents accurate assignment of size on SDS gels.

\subsection{Amino ACId SEQUence}

The complete amino acid sequence of human serum cholinesterase was determined by Edman degradation of overlapping peptides (Lockridge et al., PVI II
GGA GCA GCA GCT GCA TCC TGC ATT TCC CCG AAG TAT IAC ATG ATT TIC ACT CCT TGC AAA CTT TAC CAT CTT TGT TGC AGA GAA TCG GAA

-212 AC TGA ATG TCA GTG CAG TCC AAT TTA CAG GCT Met His Ser Lys Val Thr Ile Ile Cys Ile Arg phe Lou Phe Trp Phe Leu Leu Leu Cys Met Leu Ile Gly Lys Ser His Thr

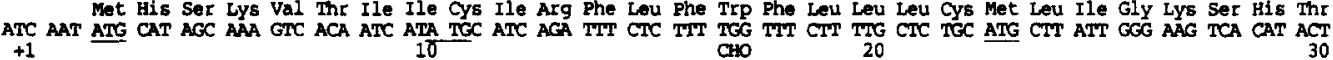
+1
Glu-Asp-Asp-Ile-Ile-Ile-Ala-Thr-LYs-Asn-Gly-Lys-Val-Arg-Gly-Met-Asn-Leu-Thr-Val-Phe-Gly-Gly-Thr-Val-Thr-Ala-Phe-Leu-GlY-

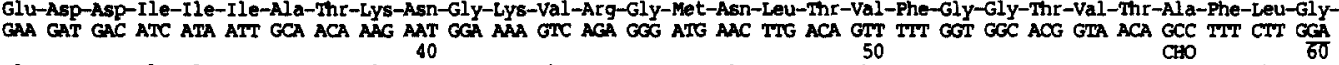
Ile-Pro-Tyr-Ala-Gln-Pro-Pro-Leu-Gly-Arg-Leu-Arg-Phe-Lys-Lys-Pro-Gln-Ser-Leu-Thr-Lys-Trp-Ser-Asp-Ile-Trp-Asn-Ala-Thr-LysATT CCC TAT GCA CAG CCA CCT CTT GGT AGA CTT CGA TTC AAA AAG CCA CAG TCT CTG ACC AAG TGG TCT GAT ATT TGG AAT GCC ACA AAA
ECO RI Tyr-Ala-Asn-Ser-Cys-Cys-Gln-Asn-Ile Asp|Gln-Ser-Phe-Pro-Gly-Phe-His-Gly-Ser-Glu-Met-Trp-Asn-Pro-Asn-Thr-Asp-Leu-Ser-Glu-

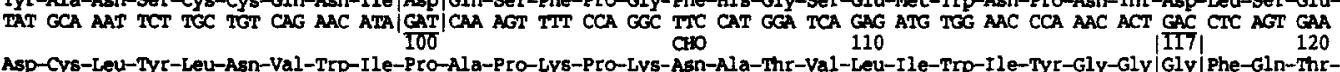
Asp-CYs-Leu-Tyr-Leu-Asn-Val-Trp-Ile-Pro-Ala-Pro-Lys-Pro-Lys-Asn-Ala-Thr-Val-Leu-Tle-Trp-Ile-Tyr-Gly-Gly|Gly|Phe-Gln-Thr-
GAC TGT TTA TAT CTA AAT GTA TGG ATT CCA GCA CCT AAA CCA AAA AAT GCC ACT GTA TIG ATA TGG ATT TAT GGT GGT|GGT|TIT CAA ACT

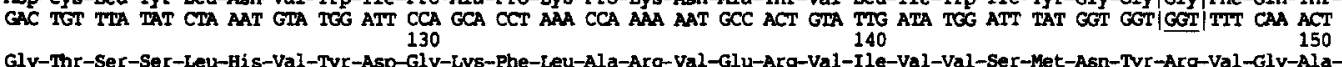
Gly-Thr-Ser-Ser-Leu-His-VaI-Tyr-Asp-GlY-Lys-Phe-Leu-Ala-Arg-Val-Glu-Arg-Val-Ile-Val-Val-Ser-Met-Asn-Tyr-Arg-Val-Gly-AlaGCA ACA TCA TCT TTA CAT GIT TAT GAT GGC AAG TIT CTG GCT CGG GIT GAA ACA GIT ATT GIA GTG TCA ATG AAC TAT ACG GTG GGT GCC
170
160 Leu-GlY-Phe-Leu-Ala-Leu-Pro-Gly-Asn-Pro-Glu-Ala-Pro-Gly-Asn-Met-Gly-Leu-Phe-Asp-Gln-Gln-Leu-Ala-Leu-Gln-Trp-Val-Gln-LYsCTA GGA TIC TTA GCT TIG CCA GCA AAT CCT GAG GCT CCA GGG AAC ATG GGT TTA TIT GAT CAA CAG TIG GCT CIT CAG TGG GTT CAA AAA 190
190 GAT CCA GGG AAC ATG GGT TTA TTI GAT CAA CAG TTG GCT CIT CAG TEG GTT CAA AAA
210 Asn-Ile-Ala-Ala-Phe-Giy-Gly-Asn-Pro-Lys-Ser-Val-Thr-Leu-Phe-Gly-Glu-SER-Ala-Gly-Ala-Ala-Ser-Val-Ser-Leu-His-Leu-Leu-Ser-
AAT ATA GCA GCC TTT GGT GGA AAT CCT AAA AGT GIA ACT CTC TIT GCA GAA AGT GCA GGA GCA GCT TCA GTT ACC CTG CAT TTG CTT TCT AAT ATA GCA GCC TTT GGT GGA AAT CCT AAA AGT GIA ACT CTC TTT GCA GAA AGT GCA GGA GCA GCT TCA GTT ACC CTG CAT TTG CTT TCT
230
Pro-Gly-Ser-His-Ser-Leu-Phe-Thr-Arg-Ala-Ile-Leu-Gin-Ser-Gly-Ser-Phe-Asn-Ala-Pro-Trp-Ala-Val-Thr-Ser-Leu-Tyr-Glu-Ala-ArgPro-Gly-Ser-His-Ser-Leu-Phe-Thr-Arg-Ala-Ile-Leu-Gin-Ser-Gly-Ser-Phe-Asn-Ala-Pro-Trp-Ala-Val-Thr-Ser-Leu-TYr-Glu-Ala-Arg-
CCT GCA AGC CAT TCA TIG TIC ACC ACA GCC ATT CTG CAA AGT GGA TCC TTT AAT GCI CCT TCG GCG GTA ACA TCT CTT TAT GAA CCT ACG

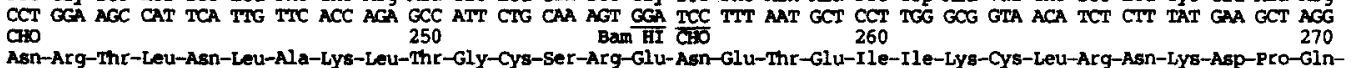
Asn-Arg-Thr-Leu-Asn-Leu-Ala-LYs-Leu-Thr-Gly-Cys-Ser-Arg-Glu-Asn-Glu-Thr-Glu-Ile-Ile-Lys-Cys-Leu-Arg-Asn-Lys-Asp-Pro-Gln-
AAC AGA ACG TTG AAC TTA GCT AAA TIG ACT GGT TGC TCT ACA GA AAT GAG ACT GA ATA ATC AAG TGT CTT AGA AAT AAA GAT CCC CAA $\begin{aligned} & \\ \text { Glu-Ile-Leu-Leu-Asn-Glu-Ala-Phe-Val-Val-Pro-Tyr-Gly-Thr-Pro-Leu-Ser-Val-Asn-Phe-Gly-Pro-Thr-Val-Asp-Gly-Asp-Phe-Leu-Thr- } & 290\end{aligned}$ Glu-Ile-Leu-Leu-Asn-Glu-Ala-Phe-Val-Val-Pro-Tyr-Gly-Thr-Pro-Leu-Ser-Val-Asn-Phe-Gly-Pro-Thr-Val-Asp-Gly-Asp-Phe-Leu-Thr-
GA ATT CTT CTG AAT GAA GCA TTT GTT GTC CCC TAT GGG ACT CCT TTG TCA GW AAC TIT GGT CCG ACC GTG GAT GGT GAT TTT CTC ACT 300
310 Asp-Wet-Pro-Asp-Ile-Leu-Leu-Glu-Leu-Gly-Gln-Phe-Lys-Lys-Thr-Gln-Ile-Leu-Val-Gly-Val-Asn-Lys-Asp-Glu-Gly-Thr-Ala-Phe-Leu-
GAC ATG CCA GAC ATA TTA CTT GA CTT GGA CAA TTT AAA AAA ACC CAG ATT TIG GTS GGT GTT AAT AAA GAT GAA GGG ACA GCT TTT TTA 990
340 CA0 Val-Tyr-Gly-Ala-Pro-Gly-Phe-Ser-Lys-Asp-Asn-Asn-Ser-Ile-Ile-Thr-Arg-Lys-Glu-Phe-Gln-Glu-Gly-Leu-Lys-Ile-Phe-Phe-Pro-GlyGTC TAT GGT GCT CCT GCC TIC ACC AAA GAT AAC AAT AGT ATC ATA ACT ACA AAA GAA TTT CAG GAA GGT TIA AAA ATA TIT TIT CCA GCA 1080 Val-Ser-Glu-Phe-Gly-Lys-Glu-Ser-Ile-Leu-Phe-Bis-Tyr-Thr-Asp-Trp-Val-Asp-Asp-Gln-Arg-Pro-Glu-Asn-Tyr-Arg-Glu-Ala-Leu-Gly-
GTG AGT GAG TTT GCA AAG GAA TCC ATC CTT TTT CAT TAC ACA GAC TGG GIA GAT GAT CAG AGA CCT GAA AAC TAC CGT GAG GCC TTG GGT 1170
400 Asp-Val-Val-Gly-Asp-Tyr-Asn-Phe-Ile-Cys-Pro-Ala-Leu-Glu-Phe-Thr-Lys-Lys-Phe-Ser-Glu-Trp-Gly-Asn-Asn-Ala-Phe-Phe-Tyr-TyrPhe-Glu-His-Arg-Ser-Ser-Lys-Leu-Pro-Tro-Pro-Glu-Tro-Met-Gly-Val-Met-His-Gly-Tyr-Glu-Ile-Glu-Phe-Vai-Phe-Gly-Leu-Pro-Leu-
440

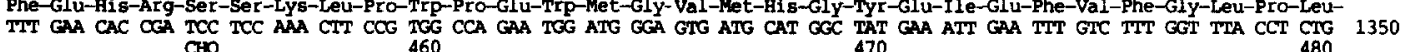
Glu-Arg-Arg-Asp-Asn-Tyr-Thr-Lys-Ala-Glu-Glu-Ile-Leu-Ser-Arg-Ser-Ile-Val-Lys-Arg-Trp-Ala-Asn-Phe-Ala-Lys-Tyr-Gly-Asn-ProGA AGA AGA GAT AAT TAC ACA AAA GCC GAG GAA ATT TTG AGT AGA TCC ATA GIG AAA CGT TGG GCA AAT TTT GCA AAA TAT GGG AAT CCA 1440 CHO 0 CHO 500 510 Asn-Glu-Thr-Gin-Asn-Asn-Ser-Thr-Ser-Trp-Pro-Val-phe-Lys-Ser-Thr-Glu-Gln-Lys-TYr-Leu-Thr-Leu-Asn-Thr-Glu-Ser-Thr-Atg-Ile-
AAT GAG ACT CAG AAC AAT AGC ACA ASC TGG CCT GTC TIC AAA ACC ACT GAA CAA AAA TAT CTA ACC TIG AAT ACA GAG TCA ACA AGA ATA 1530
520 Met-Thr-Lys-Leu-Arg-Ala-Gln-Gin-Cys-Arg-Phe-Trp-Thr-Ser-Phe-Phe-Pro-Lys-Val-Leu-Glu-Met-Thr-Gly-Asn-Ile-Asp-Glu|Ala GluATG ACG AAA CTA CGT GCT CAA CAA TGT OGA TTC TGG ACA TCA TIT TTT CCA AAA GTC TTG GAA ATG ACA GCA AAT ATT GAT GAA|GCA|GAA 1620 Trp-Glu-Trp-Lys-Ala-Gly-Phe-His-Arg-Trp-Asn-Asn-Tyr-Met-Met-Asp-Trp-Lys-Asn-GIn-Phe-Asn-Asp-Tyr-Thr-Ser-Lys-Lys-Glu-SerTGG GAG TGG AAA GCA GGA TIC CAT CGC TGG AAC AAT TAC ATG ATG GAC TGG AAA AAT CAA TTT AAC GAT TAC ACT AGC AAG AAA GAA AGT 1710 Cys-Val-Gly-Leu $\star \star * *$

TGT GTG GGT CTC TAA TTA ATA GAT TTA CCC TTT ATA GAA CAT ATT T2T CTT TAG ATC AAg GCA AaA ATA TCA GGA GCT TTT TTA CAC ACC 1800 TAC TAA AAA AGT TAT TAT GTA GCT GA ACA AAA ATG CCA GAA GGA TAA TAT TGA TTC CTC ACA TCT TTA ACT TAG TAT TTT ACC TAG CAT 1890 TTC AAA ACC CAA ATG GCT AGA ACA TGT TTA ATT AAA TIT CAC AAT ATA AAG TTC TAC AGT tAA TTA TGT GCA TAT TAA AAC AAT GGC CTG 1980 GTT CAA TTT CTT TCT TTC CTT at aAd TTT AAG TIT TIT CCC CCC AAA ATT ATC AGT GCT CTG CTT TTA GTC ACG TGT ATT TTC ATT ACC 2070

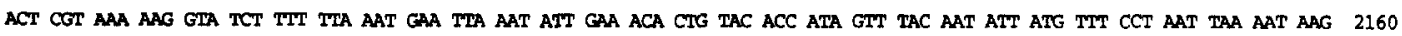

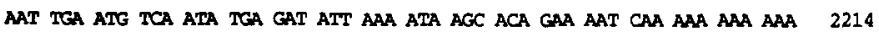

FIG. 8. Amino acid and nucleotide sequence of human cholinesterase of the usual genotype. The amino acid sequence was determined by Edman degradation of overlapping peptides (Lockridge et al., 1987b). The N-terminal amino acid of the protein circulating in human serum is glutamic acid (Glu +1$)$. Carbohydrate chains (CHO) are attached to the nine indicated asparagines. The active site serine is Ser 198. The cDNA contains a total of 2426 nucleotides (McTiernan et al., 1987). Five ATG codons in the $5^{\prime}$ region are underlined because they are potential translation initiation sites. The most likely start site is at Met-28, yielding a signal peptide of 28 amino acids. The polyadenylation signal, aataaa, at nucleotides 2002-2007, is in lower case letters. Restriction sites Pvu II, Eco RI, Bam HI, Xba I, and Hinc II are underlined. Three amino acids are enclosed in a box: Asp 70, Gly 117, and Ala 539. In atypical cholinesterase Asp 70 is altered to Gly 70 . In the $\mathbf{K}$ variant Ala 539 is $\mathrm{Thr} 539$. In silent cholinesterase Gly 117 has a frame shift mutation. 
1987b). Figure 8 shows the 574 amino acids in each subunit. The active site serine, identified by alkylation with tritiated DFP, is serine 198.

The cholinesterase used for sequencing was purified from $150 \mathrm{~L}$ of pooled human plasma donated by approximately 600 random individuals. The amino acid sequence therefore represents the usual cholinesterase genotype. If a rare variant happened to be included in the pooled sample then the peptide containing the altered amino acid would have separated from the usual peptide on HPLC and would not have been sequenced because its yield would have been too low. The techniques of HPLC purification of peptides and sequencing by Edman degradation would, however, have revealed a polymorphism with a frequency of about $50 \%$ if it existed. However, no common polymorphism was found.

\subsection{DisULFIDE BONDS}

There are 8 cysteines in each subunit. Six cysteines form three internal disulfide loops between Cys 65-92, 252-263, and 400-519 (Lockridge et al., 1987a; Fig. 9). The number of amino acids in each of the disulfide loops is exactly the same in human cholinesterase and in Torpedo acetylcholinesterase (MacPhee-Quigley et al., 1986).

The cysteine near the carboxyl terminal, Cys 571, forms a disulfide bond with Cys 571 of an identical subunit. This accounts for the existence of the 170,000 dalton dimer observed on SDS gel in the absence of reducing agent. The interchain disulfide bond is near the surface of the molecule and can be selectively reduced and alkylated (Lockridge et al., 1979). It is also easily clipped off by proteolytic agents (Lockridge and La Du, 1982). The molecule remains a tetramer even after the interchain disulfide bond has been removed by proteolysis or has been selectively reduced and alkylated. One function of the interchain disulfide bond is to stabilize the molecule. This is measured by heat stability tests which show that intact cholinesterase has a half-life of $54 \mathrm{~min}$ at $55^{\circ} \mathrm{C}$, whereas selectively reduced and alkylated cholinesterase has a half-life of $16 \mathrm{~min}$ at $55^{\circ} \mathrm{C}$ (Lockridge et al., 1979).
Cholinesterase may contain one free sulfhydryl group at Cys 66. Tomlinson and Kinsch (1989) titrated one free sulfhydryl using a fluorescent sulfhydryl-specific reagent. However, Cys 66 did not react with iodoacetic acid (Lockridge et al., 1987a) suggesting that Cys 66 is located in a hydrophobic pocket.

Amino acid composition analysis as well as sequence analysis gave no evidence to suggest that Cys 66 might be bound to a remnant of a collagen tail. This was a possibility because in acetylcholinesterase the collagen tail is covalently attached to the catalytic subunit via an as yet unidentified disulfide bond. Torpedo acetylcholinesterase has one free sulfhydryl, Cys 231 (MacPhee-Quigley et al., 1986), in a location quite different from the free sulfhydryl, Cys 66, of human cholinesterase.

\subsection{CARBohydRates}

Nine carbohydrate chains are attached to asparagines at positions $17,57,106,241,256,341,455,481$, and 486 in each subunit (Lockridge et al., 1987b; Fig. 9). The number and location of carbohydrate chains were determined during amino acid sequencing. Thus, the cholinesterase molecule contains 36 carbohydrate chains per tetramer. The average carbohydrate chain terminates with 2 sialic acids. Thus, the cholinesterase molecule has a negative charge of minus 72. This large negative charge accounts for its low isoelectric point of approximately 4.0 (Das and Liddell, 1970). Advantage of this unusually low $\mathrm{p} I$ value is taken during purification on anion exchange chromatography where cholinesterase is one of only a few proteins that binds to DEAE resin at $\mathrm{pH} 4.0$.

The finding of nine carbohydrate chains per subunit is consistent with the report by Haupt et al. (1966) that $23.9 \%$ of the weight of human serum cholinesterase is due to carbohydrate. These authors reported a carbohydrate composition of $9.3 \%$ galactose plus mannose, $8.4 \%$ acetylhexosamine, $6.0 \%$ acetylneuraminic, and $0.2 \%$ fucose. This can be calculated to represent 50 residues of galactose plus mannose per subunit, 35 acetylhexosamines, 18

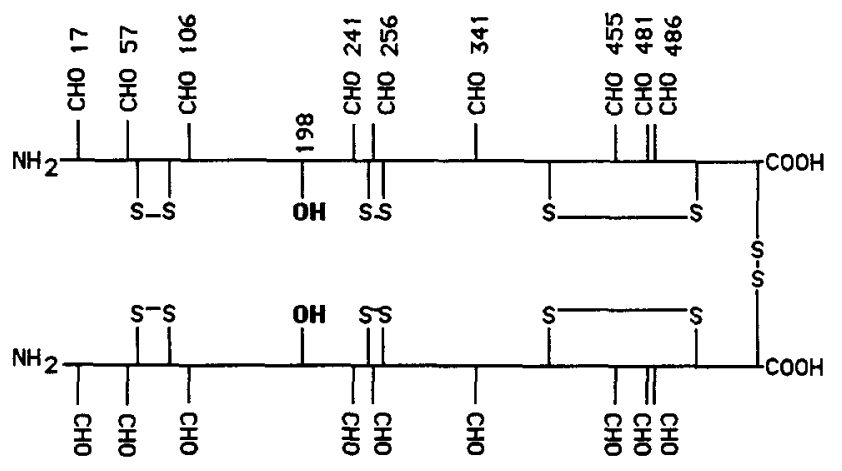

FIG. 9. Two identical subunits joined by interchain disulfide. The subunits are covalently linked through a disulfide bond at Cys 571. Other disulfide bonds are between Cys 65-92, 252-263, and 400-519 (Lockridge et al., 1987a). The nine carbohydrate chains (CHO) are attached to asparagines. The active site serine is serine 198 . The carboxyl terminus is residue 574 . Carbohydrates contribute $23.9 \%$ to the molecular weight, which is 85,534 per glycosylated subunit. 
acetylueuraminic acids (sialic acid), and 1.2 residues of fucose per subunit. These data suggest that the carbohydrate chains are the complex type terminating in sialic acid.

With one exception, all asparagines in the cholinesterase sequence that could theoretically be attached to carbohydrate were found to be glycosylated. The single exception was asparagine 485 , which is adjacent to the glycosylated asparagine 486 . It is not surprising that asparagine 485 is not glycosylated since $N$-glycosidic linkages are commonly separated by several amino acids and do not occur on adjacent asparagines.

\subsection{Subunit Organization}

The majority of cholinesterase in human serum (approximately 95\%) is a water-soluble, globular G4 form, having no glycolipid anchor and no collagen tail. It is a tetramer of four identical subunits (Lockridge et al., 1987b). There are four active sites per molecule (Lockridge and La Du, 1978). Figure 10 is a schematic diagram showing the four subunits connected by two interchain disulfide bonds (Lockridge et al., 1979). The interchain disulfide bonds are not required for the tetrameric organization of the subunits; the molecule is a tetramer even when the interchain disulfide bonds are reduced and alkylated, or removed altogether by proteolysis (Lockridge and La Du, 1982).

Strong noncovalent bonds hold the four subunits together. The tetramer cannot be dissociated into active subunits. To generate subunits having cholinesterase activity one must use proteases, such as trypsin, or sonication. The resulting subunits have apparent molecular weights that are indistinguishable from the molecular weight of intact subunits, though it can be shown that a small peptide has been cleaved off (Lockridge and La Du, 1982).

Approximately 5\% of the cholinesterase in human serum consists of monomer and dimers, some of which may be degradation products due to proteolysis (Lockridge and La Du, 1982). Other tissues, for example muscle, contain asymmetric forms with a collagen-like tail, similar to the asymmetric forms of acetylcholinesterase (Silman and Futerman, 1987).

\subsection{ACTIVE Site}

When cholinesterase is exposed to diisopropyl fluorophosphate (DFP), the enzyme loses all activity, and a single amino acid becomes alkylated. The alkylated amino acid is the active site serine located 198 amino acids from the $\mathrm{N}$-terminal (Lockridge et al., 1987b; Lockridge and La Du, 1986). To date only Ser 198 is known to belong to the active site. Other amino acids that participate in catalysis or substrate binding are speculated to be aspartic acid, histidine, tyrosine, tryptophan, arginine, and lysine (Boopathy and Balasubramanian, 1985). Aspartic acid and histidine may be part of a catalytic triad similar to the catalytic triad, Asp-His-Ser, of the serine proteases. Tryptophan and tyrosine may be in the hydrophobic binding pocket (Cohen et al., 1959; Chan et al., 1974).

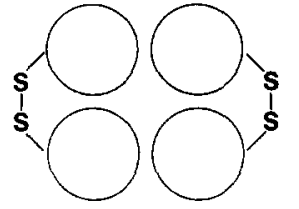

FIG. 10. Subunit organization of human serum cholinesterase. Four identical subunits are held together by noncovalent bonds. The subunits are arranged as a dimer of dimers with each dimer containing two subunits joined by a single interchain disulfide bond at Cys 571. The enzyme remains fully active and is still a tetramer after the interchain disulfides have been selectively reduced and alkylated. There is one active site per subunit. (Lockridge et al., 1979). Reprinted with the permission of the copyright holder, The American Society for Biochemistry and Molecular Biology, Bethesda.

One approach to identifying amino acids in the active site is to compare the amino acid sequences of the one cholinesterase and four acetylcholinesterases which have been sequenced to date (Lockridge et al., 1987b; Schumacher et al., 1986; Hall and Spierer, 1986; Sikorav et al., 1987; Smyth et al., 1988), and to assume that residues involved in catalysis must be conserved. Only two histidines are conserved and these are His 423 and His 438 (Fig. 11). Both histidines may be important for catalysis. Krupka (1966a) found two histidines in the active center. One with a $\mathrm{p} K$ of 5.5 functioned in acetylation and was located at least $9 \AA$ from the anionic site, while the other with a $\mathrm{p} K$ of 6.3 functioned in deacetylation and was located within $5 \AA$ of the anionic site.

\section{FAMILY OF SERINE ESTERASES}

Cholinesterase activity is irreversibly inhibited by DFP due to alkylation of the active site serine. This characteristic is shared by the family of serine proteases which includes trypsin, chymotrypsin, and the blood coagulation factors. For a long time it was speculated that the cholinesterases may belong to the family of serine proteases. Determination of the complete amino acid sequence of human serum cholinesterase as well as of several acetylcholinesterases has shown that there is no significant sequence homology between the cholinesterases and the serine proteases. In addition, there is no resemblance between their patterns of disulfide bonds. It appears, instead, that the cholinesterases belong to a distinct family of serine esterases. Figure 11 is a schematic diagram of proteins that have sequence homology with cholinesterase and includes chymotrypsinogen for comparison. Besides the cholinesterases, the family includes a rabbit liver microsomal esterase, esterase- 6 from Drosophila, and the carboxyl terminal portion of thyroglobulin. There are three disulfide loops in the cholinesterases and in thyroglobulin and the loops are similarly located. Rabbit esterase and Drosophila esterase- 6 have the first two disulfide loops, but not the third. The number of amino acids in each of the disulfide loops is similar. In contrast, chymotrypsinogen has 5 disulfide loops arranged in a pattern which is very different from the pattern in the cholinesterases. 

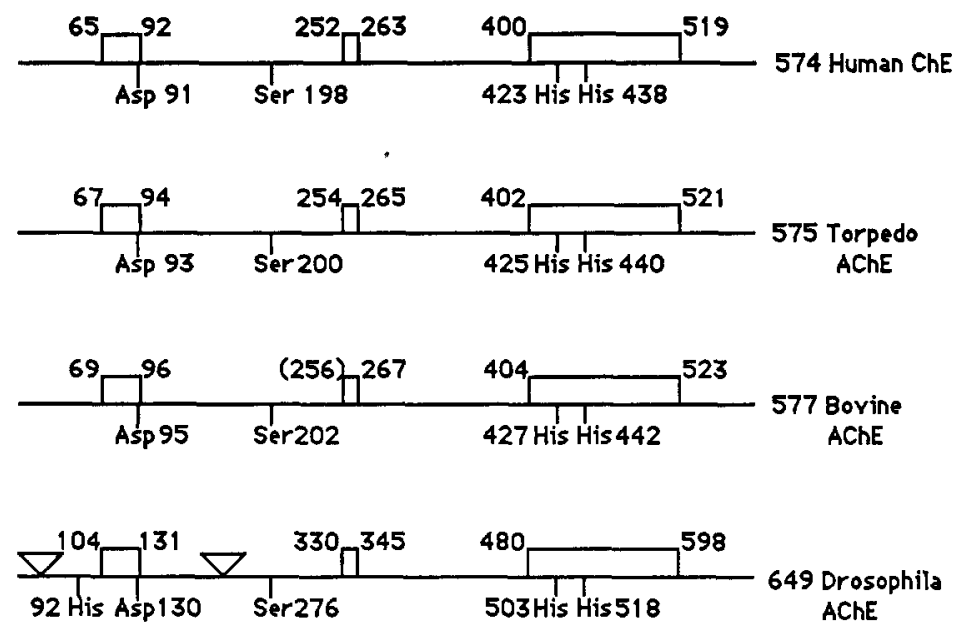

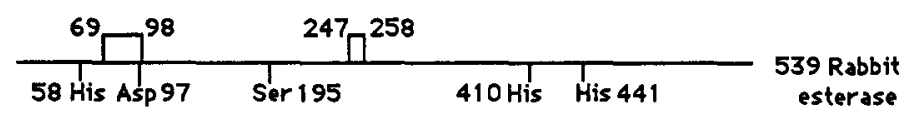
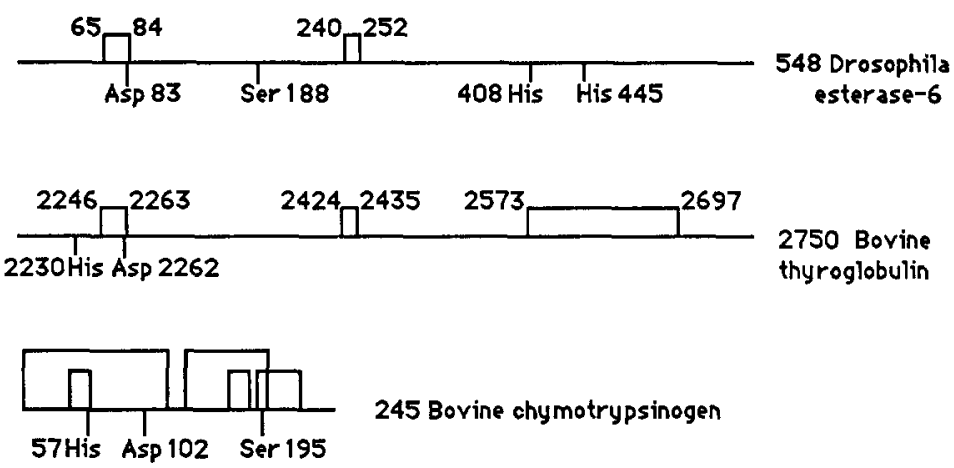

FIG. 11. The cholinesterase family of serine esterases is distinct from the serine protease family. This figure compares proteins that have sequenced homology with human cholinesterase with one member of the serine protease family, namely with bovine chymotrypsinogen. Boxes represent disulfide bonds. Conserved residues are shown. These include the active site serine, an aspartic acid that may be part of the catalytic triad, and histidines that may be important for catalysis. The number at the end of each line is either the total number of amino acids in the mature protein or the number of amino acids deduced from cDNA including the signal peptide. The amino acid sequence of Torpedo AChE (Schumacher et al., 1986; Sikorav et al., 1987) is 54\% identical to the sequence of human ChE, fetal bovine AChE $50 \%$ (Smyth et al., 1988), Drosophila melanogaster AChE 38\% (Hall and Spierer, 1986), rabbit liver microsomal esterase 30\% (Korza and Ozols, 1988), Drosophila esterase-6 19\% (Oakeshott et al., 1987), and bovine thyroglobulin $28 \%$ (Lockridge et al., 1987b). In contrast, bovine chymotrypsinogen has no significant sequence identity. Parentheses are placed around Cys 256 of bovine AChE because this amino acid has not yet been sequenced, and its presence is implied.

The active site serine is in position 198 in human cholinesterase and in a similar position in each of the proteins including chymotrypsinogen. Each of the family members has aspartic acid immediately adjacent to Cys in the first disulfide loop. The amino acid sequence around this aspartic acid is highly conserved, being Ser-Glu-Asp-Cys-Leu-Tyr-Leu in six proteins: human cholinesterase, acetylcholinesterase from Torpedo californica and marmorata, acetylcholinesterase from fetal bovine serum, liver microsomal esterase from rabbit, and bovine thyroglobulin. In Drosophila acetylcholinesterase the conserved amino acids are Ser-Glu-Asp-Cys-Leu-Tyr, and in Drosophila esterase-6 they are Glu-Asp-Cys-Leu.
We speculate that Asp 91 of human cholinesterase belongs to the catalytic triad, Asp/His/Ser.

Two histidines, His 423 and His 438 , are conserved in the proteins in Fig. 11. Only thyroglobulin is missing these histidines and thyroglobulin has no esterase activity. We speculate that both histidines are important for catalysis. These two histidines are absent in the serine proteases, exemplified by chymotrypsinogen in Fig. 11, because none has a homologous protein region. Instead, the serine proteases have histidine at position 57 . Histidine 57 is missing in human cholinesterase and Torpedo acetylcholinesterase, but seems to be conserved in Drosophila acetylcholinesterase, rabbit esterase, and in thyro- 
globulin. These comparisons suggest that the cholinesterases belong to a family of serine esterases that is structurally distinct from the family of serine proteases.

\section{THE USUAL CHOLINESTERASE GENE}

\section{1. cDNA SEQUENCE}

The cDNA for human cholinesterase (Fig. 8) was isolated independently by two laboratories. Both laboratories used oligonucleotide probes to isolate cholinesterase clones. Prody et al. (1987) found one clone in a cDNA library from fetal brain and an overlapping clone in a library from fetal liver. McTiernan et al. (1987) isolated overlapping clones from a cDNA library prepared from a newborn brain. The nucleotide sequences from the two laboratories were nearly identical. The difference in developmental age of the tissues from which the mRNA was prepared, and the difference in tissue of origin, did not affect the nucleotide sequence. Furthermore, the coding sequence of the clones corresponded exactly to the known amino acid sequence of adult serum cholinesterase. It can be concluded that cholinesterase in human embryonic, newborn, and adult tissues has the same amino acid sequence.

\subsection{5' REGION}

There are multiple translation initiation sites in the 5 region of the cDNA (Fig. 8). Four of these ATG codons are in the reading frame, and one ATG is out of the frame (McTiernan et al., 1987). Only the ATG at Met -28 lies within a consensus sequence for initiator sites. On this basis the signal peptide most likely begins with Met -28 and has a total length of 28 amino acids. It is not common to have multiple ATGs in the 5 ' region and they may have some function, for example, in regulation of expression. The cDNAs for Drosophila and Torpedo acetylcholinesterase also contain multiple ATGs in the $5^{\prime}$ region though they are separated by stop codons. (Hall and Spierer, 1986; Sikorav et al., 1987).

\subsection{3' ReGION}

The 3 untranslated region contains 2 termination sites. CDNA clones have been isolated that terminate at each of these sites. One site involves the polyadenylation signal, AATAAA, at nucleotides 2002-2007 and the polyA addition site, CA, at nucleotides 2025-2026. The second polyadenylation signal appears to be a nonconsensus signal, ATTAAA, at nucleotides 2182-2187. Both McTiernan et al. (1987) and Prody et al. (1987) isolated clones which used this nonconsensus signal. The presence of multiple termination sites suggests the existence of multiple sizes of mRNA having the same coding potential.

Alternative splicing to produce different mRNAs coding for either the asymmetric or the glycolipid anchored form of acetylcholinesterase has been demonstrated for Torpedo acetylcholinesterase (Gibney et al., 1988; Sikorav et al., 1988). A similar mechanism for producing various forms of human cholinesterase is likely to exist.

\subsection{One Cholinesterase Gene}

We isolated 5 genomic clones representing the gene for human cholinesterase (Arpagaus et al., 1990). The gene is approximately 80 kilobases in length and its coding region is divided into 4 exons. Each exon was subcloned into a plasmid for the purpose of having a set of exon-specific probes. The exon probes were hybridized to blots of human genomic DNA as shown in Fig. 12. It is immediately apparent that each probe yielded only one band in most digests and no more than two bands in other digests. This result is the strongest evidence we have that there is only one gene for cholinesterase. If two or more genes existed, there would be multiple bands in each lane because intron sequences are not conserved and therefore each gene would have its own set of restriction sites. An additional supporting argument from Fig. 12 is that the sizes of the restriction fragments are in complete agreement with the restriction map which was derived from the isolated genomic clones. Had there been several genes and had we isolated just one of the cholinesterase genes, then blots of total human genomic DNA would have yielded hybridizing fragments that did not fit the map constructed for one gene. No such problems were encountered and our results are entirely consistent with the interpretation that there is only one gene for human cholinesterase.

Additional support is the sequence of the isolated genomic clones. Each exon was completely sequenced and found to agree with the cDNA sequence. A second gene would have been expected to differ from the cDNA sequence to some extent.

A final supporting argument comes from the results of gene amplification by the polymerase chain reaction. In this procedure total human DNA is present in the tube during the amplification reaction. Therefore all cholinesterase genes are amplified at the same time when the priming oligonucleotides correspond to coding regions. If there were two cholinesterase genes, for example, then DNA from a homozygous atypical would have one atypical gene and one gene that was not atypical. Sequencing of the amplified, double-stranded DNA would have shown the atypical as well as the nonatypical sequence on one sequencing gel, that is the homozygous atypical would have looked like a heterozygote on the sequencing gel. A picture of the sequencing results is shown in Fig. 6 where it is clear that the homozygous atypical reflects one gene only.

The above arguments supporting one gene are presented in detail because they are used to refute the existence of a second locus for cholinesterase. This affects the interpretation of $\mathrm{C} 5+$, which had been thought to arise from a second cholinesterase locus.

The genomic blots in Fig. 12 did not reveal the gene for acetylcholinesterase, which indicates that the gene for human acetylcholinesterase may be less than $60 \%$ identical with the gene for human cholinesterase. 


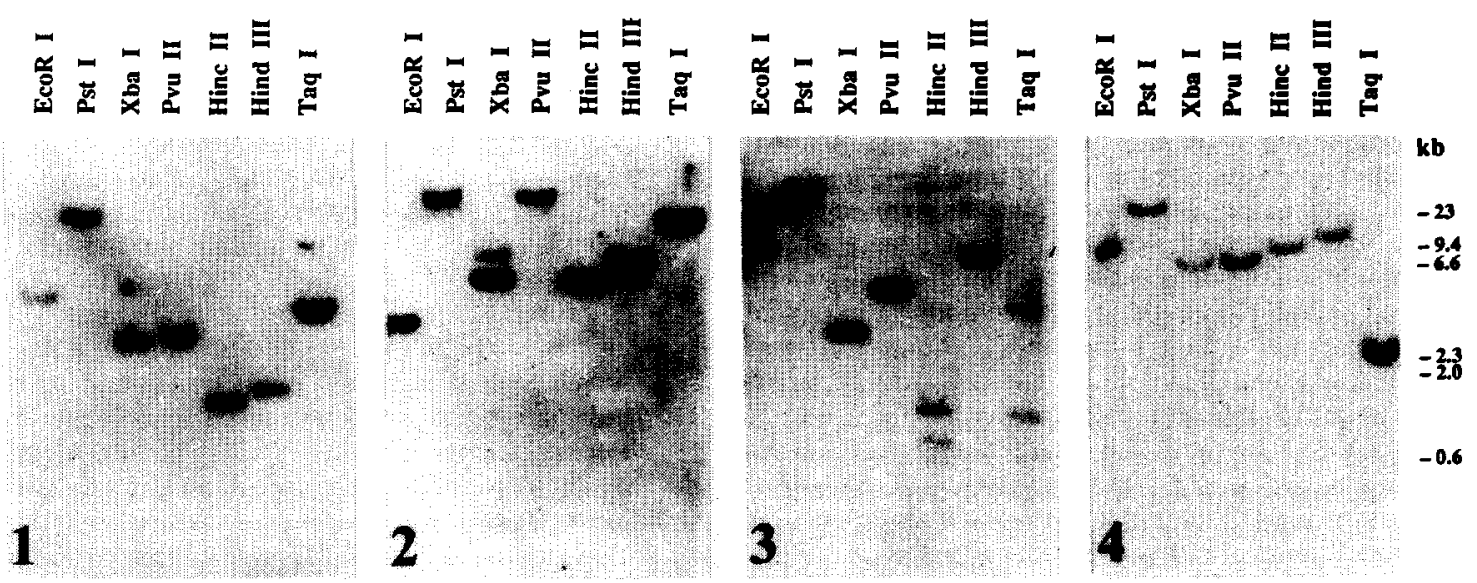

FIG. 12. Southern blots of human genomic DNA. Genomic DNA isolated from white blood cells of a single donor was digested with EcoRI, PstI, XbaI, PvuII, HinclI, Hind III, and TaqI. Each lane of the agarose gel contained $10 \mu \mathrm{g}$ DNA, which was transferred to nylon membrane (Genescreen, NEF-972). The blots were hybridized in $6 \times \mathrm{SSC}, 0.25 \%$ dry milk, at $60^{\circ} \mathrm{C}$ with P32-labeled probes at a concentration of $5 \mathrm{ng} / \mathrm{ml}$. Blots were washed with three fluid changes in $2 \times \mathrm{SSC}, 0.1 \% \mathrm{SDS}$ at $60^{\circ} \mathrm{C}$ for $1 \mathrm{hr}$ each, and exposed for $16 \mathrm{hr}$ with intensifying screen. Exon specific probes were prepared from genomic clones. In panel $I$ the probe was a $0.8 \mathrm{~kb}$ PstI/HindlII fragment including Exon 1 . In panel 2 the probe was a $2.4 \mathrm{~kb}$ EcoRI/EcoRI fragment including Exon 2 . In panel 3 the probe was a $1.7 \mathrm{~kb}$ EcoRI $/ \mathrm{XbaI}$ fragment including Exon 3 . In panel 4 the probe was a $0.7 \mathrm{~kb} \mathrm{Rsal} / \mathrm{Rsa}$ I fragment including Exon 4 . The blots show only one gene for human cholinesterase (Arpagaus et al., 1990). Reprinted with the permission of the copyright holder, the American Chemical Society, Washington, D.C.

\subsection{Location on Chromosome 3}

Human cholinesterase is on chromosome 3 . This result was deduced from the linkage of genetic variants of cholinesterase with transferrin, and the known location of transferrin on the long arm of chromosome 3 in region 3q21-25 (Yang et al., 1984). The linkage group includes transferrin, cholinesterase, ceruloplasmin, and alpha2HS glycoprotein. This location was confirmed by Soreq et al. (1987) by hybridization experiments with cholinesterase cDNA. A second, weaker hybridization site was found on chromosome 16 by Soreq et al. (1987), who speculated that chromosome 16 may contain the gene for C5 + cholinesterase. Our results do not agree with this interpretation as we find only one cholinesterase gene.

\subsection{Cholinesterase in Various Tissues}

The cholinesterase in serum is generally considered to be synthesized in the liver. New supporting evidence is the isolation of a cholinesterase CDNA clone from a human liver library (Prody et al., 1987), thus demonstrating that the liver must have mRNA for cholinesterase. A second supporting argument is the finding that liver transplantation into a patient whose cholinesterase genotype was heterozygous atypical-usual resulted in the circulation of cholinesterase having the homozygous usual genotype (Khoury et al., 1987).

The amino acid sequence deduced from the nucleotide sequence of cholinesterase cDNA clones isolated from liver (Prody et al., 1987) and brain (McTiernan et al., 1987) was the same as the amino acid sequence of the protein isolated from serum (Lockridge et al., 1987b). This leads to the conclusion that cholinesterase in three different human tissues, in liver, brain, and serum, is identical.

\section{ATYPICAL CHOLINESTERASE}

\subsection{Purification of Atypical Cholinesterase Protein}

Three liters of plasma were collected from a single individual over 5 years. The plasma was stored at $-20^{\circ} \mathrm{C}$. The first step of purification, ion exchange chromatography at $\mathrm{pH} 4.0$, worked as well for atypical cholinesterase as it did for usual cholinesterase. The second step was affinity chromatography on procainamide-Sepharose. Atypical cholinesterase eluted at a lower salt concentration than usual cholinesterase from the affinity column, and because of this the atypical enzyme was not pure. A major contaminant having a subunit weight of 45,000 could be separated on either Sephacryl S-300 or ion exchange at $\mathrm{pH} 7$ by including $50 \mathrm{~mm}$ dithiothreitol in the buffer. Our best preparation was estimated to be $84 \%$ pure. When the active site tryptic peptide was isolated from this preparation the peptide was not full-length and terminated in glycine rather than in arginine. This suggested that the contaminants in even our purest atypical cholinesterase preparation included proteases.

\subsection{Specific Activity of Atypical Cholinesterase}

At saturating substrate concentration atypical cholinesterase has the same activity per active site as usual cholinesterase (Lockridge and $\mathrm{La} \mathrm{Du}$, 1978; Eckerson et al., 1983a). Therefore, the specific activity of pure atypical cholinesterase should be $200 \mathrm{units} / \mathrm{mg}$ when activity is extrapolated to $V_{\max }$ 
conditions. At $0.05 \mathrm{~mm}$ benzoylcholine, the concentration for routine assays, the activity of atypical cholinesterase is $76 \%$ of $V_{\max }$, whereas the activity of usual cholinesterase is $97 \%$ of $V_{\max }$. Thus, electrophoretically pure atypical cholinesterase is expected to have a specific activity of 150 units $/ \mathrm{mg}$, measured with $0.05 \mathrm{~mm}$ benzoylcholine. The highest specific activity we have obtained is 126 units $/ \mathrm{mg}$.

On SDS gel electrophoresis the mobility of atypical cholinesterase was the same as the mobility of usual cholinesterase. Therefore, there are no apparent differences in subunit molecular weight or in subunit organization. In addition there are no differences in sialic acid content, heat stability, and immunoreactivity with polyclonal (Eckerson et al., 1983a) and monocloncal antibodies (Brimijoin et al., 1983). No physical differences between usual and atypical cholinesterases could be found, leading to the expectation that a single amino acid alteration or very few amino acid alterations were responsible for the observed differences in kinetic properties.

\subsection{Atypical Cholinesterase Mutation Affects the Binding of Positively Charged Ligands}

The evidence on the nature of the alteration in atypical cholinesterase is summarized by the following.

(1) The $K_{\mathrm{m}}$ values for positively charged substrates are different for usual and atypical cholinesterase. Atypical has a lower affinity for positively charged substrates (see Table 3 ). The $K_{\mathrm{m}}$ values for the neutral substrates, $O$-nitrophenyl butyrate and alpha-naphthyl acetate, are the same for usual and atypical cholinesterases. This shows that the binding site for positively charged substrates has been altered in atypical cholinesterase, and that this alteration does not affect the binding of neutral substrates.

(2) The binding constants show that atypical cholinesterase has a lower affinity for positively charged inhibitors than does usual cholinesterase (see Table 4).

(3) The mechanism of reaction with $\mathrm{N}$-methyl-(7dimethylcarbamoxy) quinolinium iodide, a positively charged carbamyl ester, was found to be the same for atypical and usual cholinesterase (Lockridge and $\mathrm{La} \mathrm{Du}, 1978$ ). The rate determining step was decarbamylation. The rate constants for carbamylation and decarbamylation had the same value for usual and atypical. Turnover number also had the same value for usual and atypical. The only difference was in the affinity for substrate, measured as the dissociation constant, $K_{\mathrm{d}}$. The $K_{\mathrm{d}}$ for atypical cholinesterase was $5.4 \mathrm{~mm}$ while the $K_{\mathrm{d}}$ for usual cholinesterase was $0.16 \mathrm{~mm}$, thus confirming that atypical cholinesterase had a reduced affinity for the positively charged compound. This study is significant because the dissociation constant, $K_{\mathrm{d}}$, is a more reliable measure of affinity than $K_{\mathrm{m}}$, since some reaction pathways can have a $K_{\mathrm{m}}$ value that does not reflect affinity.

(4) The turnover number, that is, moles substrate hydrolyzed per minute per mole of active site under conditions where substrate is saturating, is the same for atypical and usual cholinesterases (Lockridge and La Du, 1978; Eckerson et al., 1983a) (see Table 3). Once the substrate is bound, the rate of hydrolysis is the same for atypical and usual $\mathrm{ChE}$.

TABLE 4. $\mathrm{I}_{50}$ Values for Positively Charged Inhibitors of Usual and Atypical Cholinesterase

\begin{tabular}{lcc}
\hline \multicolumn{1}{c}{ Inhibitor } & \multicolumn{2}{c}{$I_{50}(\mathrm{~mol} / \mathrm{L})$} \\
& Usual ChE & Atypical ChE \\
\hline Choline & $3.0 \times 10^{-2}$ & $5.9 \times 10^{-2}$ \\
Tetramethylammonium bromide & $2.8 \times 10^{-2}$ & $7.1 \times 10^{-2}$ \\
Meperidine & $7.6 \times 10^{-4}$ & $1.8 \times 10^{-3}$ \\
Succinylcholine $^{\mathrm{a}}$ & $9.8 \times 10^{-5}$ & $9.5 \times 10^{-3}$ \\
Procaine $^{\mathrm{a}}$ & $4.4 \times 10^{-5}$ & $5.9 \times 10^{-4}$ \\
Decamethonium $_{\text {Chlorpromazine }}$ & $1.3 \times 10^{-5}$ & $1.8 \times 10^{-3}$ \\
Dibucaine & $4.4 \times 10^{-6}$ & $7.4 \times 10^{-5}$ \\
Win 5303 & $2.7 \times 10^{-6}$ & $5.4 \times 10^{-5}$ \\
Monoquat analogh & $7.9 \times 10^{-7}$ & $2.1 \times 10^{-5}$ \\
Tetracaine & $3.4 \times 10^{-7}$ & $1.7 \times 10^{-6}$ \\
Win 4510 & $2.8 \times 10^{-7}$ & $6.3 \times 10^{-6}$ \\
Pancuronium bromide & $1.5 \times 10^{-7}$ & $5.4 \times 10^{-6}$ \\
17-desoxy analog & $1.5 \times 10^{-7}$ & $2.2 \times 10^{-5}$ \\
Neostigmine & $1.3 \times 10^{-7}$ & $2.4 \times 10^{-5}$ \\
Dibutyrate analog & $1.3 \times 10^{-7}$ & $3.3 \times 10^{-6}$ \\
Physostigmine & $1.5 \times 10^{-8}$ & $4.2 \times 10^{-6}$ \\
RO2-0683 & $1.4 \times 10^{-8}$ & $2.7 \times 10^{-7}$ \\
\hline
\end{tabular}

Win 5303 and Win 4510 are analogs of procaine. Win $5303=2-n-$ pentoxy, 4-amino-diethylaminoethylbenzoate hydrochloride. Win $4510=$ 2-n-hexoxy, 4-amino-diethylaminoethylthiobenzoate hydrochloride. RO2-0683 = dimethylcarbamate of (2-hydroxy-5-phenylbenzyl)-trimethylammonium bromide: (a) indicates esters that serve as either substrate or inhibitor: (b) indicates analog of pancuronium. From data from Kalow and Davies (1958) and from Whittaker and Britten (1981). Reprinted with the permission of the authors and the copyright holder, S. Karger, Basel. 
(5) Atypical has no response to calcium chloride, whereas usual cholinesterase hydrolyzes alpha naphthylacetate more rapidly in the presence of calcium chloride (Valentino et al., 1981).

(6) Rates of reactivation of phosphorylated cholinesterases are different, atypical being reactivated more rapidly than usual cholinesterase by $5 \mathrm{~mm}$ $\mathrm{NaF}$ (Clark et al., 1968). If the reactivating species is $\mathrm{F}^{-}$the rate of reactivation could be influenced by the anionic center, assuming that the approaching fluoride ion is repelled by the anionic center (Heilbronn, 1965).

(7) Choline increases the rate of reactivation of phosphorylated usual cholinesterase, but has no effect on phosphorylated atypical cholinesterase (Clark et al., 1968).

The above effects can be explained by the presence of an anionic site in usual cholinesterase, and the absence of an anionic site in atypical cholinesterase. The binding site for the positively charged portion of the choline ester substrate is called the anionic site. Bergmann and Wurzel (1954) suggested that the anionic site is a negatively charged amino acid such as aspartic acid or glutamic acid. The concept of an anionic site was challenged by Hasan et al. (1980) who gave evidence that the binding site in eel acetylcholinesterase fits the trimethyl group of the choline substrate. They claimed that size and shape are important, not charge. Berman and Decker (1986) refuted Hasan et al. (1980) by providing the interpretation that the anionic site exists at variable distances from the active site serine. A single nucleotide substitution has been found in atypical cholinesterase and this identifies the anionic site.

\subsection{Location of Nucleotide Alteration in Atypical ChOlinesterase}

DNA was prepared from the white cells of a person with atypical cholinesterase. A genomic clone containing $83 \%$ of the coding sequence was isolated and sequenced. A single nucleotide alteration was found at Asp 70, changing the codon from GAT to GGT (McGuire et al., 1989). This changed Asp 70 to Gly 70 (Table 5). The DNA of nineteen additional people who carried the atypical cholinesterase gene was sequenced after amplification of cholinesterase DNA by polymerase chain reaction. All twenty persons from five families were found to have the mutation at Asp 70. Figure 6 shows sequencing gel results for usual, usual-atypical, and atypical cholinesterases for the region coding for Asp 70 .

The finding that Aspartic acid 70 has been altered to Glycine in atypical cholinesterase is consistent with the idea that a negatively charged amino acid, aspartate, is involved in binding the choline portion of the ester and that neutralization of this negative charge will significantly reduce the affinity of

TABLE 5. Atypical Cholinesterase has a Mutation at Nucleotide 209

\begin{tabular}{rll}
\hline Usual & & Atypical \\
\hline GAT & $\rightarrow$ & GGT \\
Asp 70 & Gly 70 \\
\hline
\end{tabular}

cholinesterase for positively charged ligands. Torpedo acetylcholinesterase as well as fetal bovine serum acetylcholinesterase (Smyth et al., 1988) contain aspartic acid in a homologous position. However, Drosophila acetylcholinesterase has tyrosine. This raises the possibility that tyrosine may participate in the anionic site of the Drosophila enzyme.

Kieffer et al. (1986) used a photoaffinity label to alkylate amino acids at or near the anionic site of eel acetylcholinesterase. The label was found on $\mathrm{X}$ of the sequence GSXF where $X$ may be phenylalanine 330 . The homologous peptide in human cholinesterase is GTAF, and this peptide may be located near Asp 70 in three-dimensional structure.

\subsection{Atypical Cholinesterase Mutation Affects THE BINDING OF NEUTRAL LIGANDS}

Though the mutation in atypical cholinesterase primarily affects the anionic site, there is evidence that it also affects the hydrophobic binding site. The existence of a hydrophobic site was demonstrated by the following experiments. Chan et al. (1974) titrated horse serum cholinesterase which had previously been alkylated with DFP, with $N$-methylacridinium and found 0.95 identical, noninteracting, $N$-methylacridinium binding sites for each DFP binding site. They concluded that there was one anionic site per subunit. Furthermore, the tight binding constant for $N$-methylacridinium, $K_{\mathrm{d}}=3.8 \times 10^{-8} \mathrm{M}$, suggested the presence of a hydrophobic binding area close to the anionic site.

Kabachnik et al. (1970) studied the anticholinesterase potencies of a series of 108 organophosphorus inhibitors differing in the structure of their hydrocarbon side chains. For horse serum cholinesterase they concluded there were at least 2 separate hydrophobic areas in the region of the anionic site: one immediately surrounding the anionic group (A1), and the other located outside the anionic site (A2) (Fig. 13). The function of the hydrophobic area (AI) immediately surrounding the anionic group is to interact with the methyl groups attached to the nitrogen of butyrylcholine. The $\mathrm{A} 2$ area accommodates a 6-carbon chain and has a spatial configuration complementary to a tertiary butyl group. Areas $\mathrm{E} 1$ and E2 are two smaller hydrophobic areas in the vicinity of the esteratic site; the total length of $\mathrm{E} 1$ and E2 corresponds to a 7-carbon chain of straight chain structure and does not fit a tertiary butyl group.

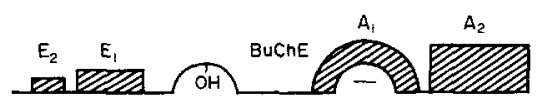

FIG. 13. Hydrophobic areas on the active surface of cholinesterase. The active site serine is indicated by $\mathrm{OH}$; the negatively charged anionic site by - . A hydrophobic area, $A_{1}$ surrounds the anionic site, and a second hydrophobic area $A_{2}$ is located at some distance from the anionic site. Area $A_{1}$ is adapted to interaction with the methyl groups attached to the nitrogen atom of choline. Two hydrophobic areas, $E_{1}$ and $E_{2}$ are in the vicinity of the esteratic site and they are complementary to a straight-chain structure having a total length of 7 carbons (Kabachnik et al., 1970). Reprinted with the permission of the authors and the copyright holder, Williams and Wilkins, Bethesda. 
The hydrophobic areas close to the anionic site, $\mathrm{Al}$ and $A 2$, may be affected by the mutation at Asp 70 in atypical cholinesterase. This is suggested by the observation that alkyl alcohols, which are hydrophobic and can be expected to bind to a hydrophobic site, have a differential effect on usual and atypical cholinesterase. For example, 1\% n-butyl alcohol elevated usual to $173 \%$ activity and depressed atypical to $49 \%$ activity (Whittaker, 1968). Many, but not all homozygous atypicals have a second nucleotide substitution (Ala $539 \rightarrow$ Thr) and this second mutation may also affect the hydrophobic areas.

\subsection{Atypical Cholinesterase Mutation Affects the Binding of Negatively Charged Ligands}

The mutation in atypical cholinesterase seems to affect a third region of the active site. At a concentration of $0.05 \mathrm{~mm}$, the negatively charged inhibitor, sodium fluoride, inhibits hydrolysis of benzoylcholine by usual cholinesterase $60 \%$ and atypical cholinesterase $20 \%$ (Harris and Whittaker, 1961). Sodium fluoride binds to two basic groups with $\mathrm{p} K_{\mathrm{a}} \mathrm{s}$ of 5.5 and 6.6 (Krupka, 1966b) and these groups may be His 423 and His 438 .

The ability of compounds with various chargespositive, neutral, and negative charges-to differentiate usual from atypical cholinesterase can be explained by assuming that the active site residues are in close juxtaposition and are therefore all affected by the negative charge of aspartic acid 70. The second mutation (Ala $539 \rightarrow \mathrm{Thr}$ ) which is present in many atypicals may also affect these interactions.

\section{THE K VARIANT}

Many, but not all, of the atypical variants had a second nucleotide substitution besides the one at Asp 70. The second substitution was at nucleotide 1615 which changed Ala 539 (GCA) to Thr 539 (ACA) (McGuire et al., 1989; Table 6). Sequencing of DNA from persons known to have the $K$ variant on the basis of inhibition indices with R02-0683, showed that all $\mathrm{K}$ variants had the mutation at Ala 539 (Bartels et al., 1989) and that it could occur independently of the Asp $70 \rightarrow$ Gly mutation. The $K$ variant was named in honor of Werner Kalow by Rubinstein et al. (1978).

\section{SILENT CHOLINESTERASE}

\subsection{Location of NuCleotide Alteration in Silent Cholinesterase}

The silent cholinesterase phenotype includes at least two variants. One type has zero activity with butyrylthiocholine and benzoylcholine and does not cross-react with antiserum to normal human serum

TABLE 6. $K$ Variant has a Mutation at Nucleotide 1615

\begin{aligned} & \hline Usual K variant \\ & \hline GCA $\rightarrow \begin{array}{l}\text { ACA } \\ \text { Ala 539 }\end{array} \\ &$ Thr 539 \\ & \hline\end{aligned}

TABLE 7. Silent-1 Cholinesterase has a Frame Shift Mutation at Nucleotide 351

\begin{tabular}{rll}
\hline Usual & & Silent \\
\hline GGT & $\rightarrow$ & $\begin{array}{l}\text { GGAG } \\
\text { frame shift }\end{array}$ \\
\hline
\end{tabular}

cholinesterase. A second type has $2 \%$ of normal activity and is recognized by cholinesterase antibodies (Rubinstein et al., 1970). Additional silent variants probably exist based on band patterns seen on polyacrylamide gel electrophoresis stained for esterase activity (Altland and Goedde, 1970).

DNA of silent cholinesterase from two sources was sequenced and found to have the same mutation at glycine 117 (McGuire et al., 1989). GGT was changed to GGAG (Table 7). This frame shift mutation creates a stop codon 12 amino acids later at codon 129 . The absence of activity in this silent cholinesterase is explained by the fact that the protein has only 128 amino acids rather than 574 . The active site serine at position 198 is not present in this silent cholinesterase. The calculated molecular weight of the prematurely terminated silent cholinesterase is 21,000 , a value which includes the weight of three carbohydrate chains. One patient with this silent cholinesterase was a Persian female who experienced prolonged apnea after receiving succinylcholine. Her serum was tested for cholinesterase activity with benzoylcholine and found to have zero activity. The same mutation was found in a male member of an American-Italian family; his genotype was heterozygous for usual/silent cholinesterase.

\section{QUESTIONS THAT REMAIN UNANSWERED OR CONTROVERSIAL}

(1) What drugs should be avoided by persons who have a rare cholinesterase genotype? It is clear that succinylcholine is one such drug. Another candidate is mivacurium, a new muscle relaxant which is in the testing stage and has not yet been approved for human use. The local anesthetics procaine and chloroprocaine do not seem to present a clinical problem partly because of the way they are administered, intramuscularly or subcutaneously with a vasoconstrictor, and partly because these drugs have been replaced by lidocaine. What other drugs belong on this list? Should people with atypical cholinesterase be especially careful with cocaine and heroin? In test tube experiments atypical cholinesterase has a lower affinity for both drugs, but it is not known whether this would lead to serious consequences in vivo. For example, the question arises whether people who have died after a first time use of cocaine might have had an abnormal cholinesterase genotype or reduced cholinesterase activity. A study underway in Toronto is testing cholinesterase activity in hospitalized cocaine users (Devenyi, 1989).

(2) Are rare cholinesterase variants associated with any disease? Reports based on small numbers of people have turned out to be incorrect. Results 
available to date lead to the conclusion that there is no link between a rare cholinesterase variant and any disease. Furthermore, no cause and effect relationship has been found between changes in cholinesterase or acetylcholinesterase levels and nervous system disorders such as Alzheimers, Huntington's, and brain tumors (Rakonczay, 1988). The Danish Cholinesterase Research Unit has approximately 7000 succinylcholine-sensitive persons in its files and an examination of these files is in progress to search for possible association with a disease.

(3) The physiological function of cholinesterase is unknown. The fact that people with zero cholinesterase activity (silent variant) are healthy and probably have a normal life-expectancy may suggest that cholinesterase is unimportant. However, an alternative explanation might be that its function is so important that a backup system of esterases exists. High levels of cholinesterase are found in embryonic tissues and a role in development is suspected (Layer and Sporns, 1987). A role in lipoprotein metabolism (Kutty et al., 1977) also seems possible as it is known that cholinesterase activity is high in obesity and low in malnutrition.

(4) Questions remain about the cholinesterase protein and gene. The X-ray structure has not yet been done. A three-dimensional understanding of the active site structure should explain the tight binding of bisquaternary inhibitors such as succinyldicholine and decamethonium to usual but not to atypical cholinesterase. Though Asp 70 is part of the anionic site, is there a second anionic site as well? Asp and His of the catalytic triad Ser-Asp-His, have been tentatively identified by sequence homology. The cholinesterase in serum is soluble, but the cholinesterase in brain and muscle is membrane bound. To explain the synthesis of more than one cholinesterase from a single gene alternative splicing is hypothesized, but has not yet been proven. Some variants are not yet understood at the DNA level, though it is anticipated that rapid progress will be made on the fluoride, $\mathrm{H}, \mathrm{J}$, and Cynthiana variants.

Acknowledgements - This work was supported in part by the US Army Medical Research and Development Command, Contract No. DAMDI7-86-C-6037 (to O. L.), Contract DAMD17-89-C-9022 (to O. L.) and Public Health Service Grant GM 27028 (to Bert N. La Du). A salute to Bert N. La Du, who could have written this chapter but let his younger associate do it. We have worked together for 15 years and now Bert is retiring, satisfied that his laboratory finally identified the structural alteration in atypical cholinesterase as well as some of the other variants. Our work is a continuation of work started by Dr Werner Kalow and it is therefore a special pleasure to have Dr Kalow edit this review. Discussions with Dr Frank Jensen and Dr W. Kalow clarified clinical points regarding succinylcholine.

\section{REFERENCES}

Altland, K. and Goedde, H. W. (1970) Heterogeneity in the silent gene phenotype of pseudocholinesterase of human serum. Biochem. Genet. 4: 321-338.
Arpagaus, M., Kott, M., Vatsis, K. P., La Du, B. N. and LOCKRIDGE, O. (1990) Structure of the gene for human butyrylcholinesterase: evidence for a single copy. Biochemistry 29: 124-131.

AZAR, I. and BETCHER, A. M. (1981) Response of a patient with atypical pseudocholinesterase to small intermittent succinyldicholine doses. Anesthesiology 54: 519-520.

Baraka, A., Haroun, S., Bassili, M. and Abu-Haider, G. (1975) Response of the newborn to succinylcholine injection in homozygotic atypical mothers. Anesthesiology 43: 115-116.

Bartels, C. F., Van der Spek, A., Lockridge, O. and LA DU, B. N. (1989) A polymorphism (K variant?) of human serum cholinesterase at nucleotide 1615 , coding for Ala/Thr 539. FASEB J. 3: A741.

BergmanN, F. and Wurzel, M. (1954) The structure of the active surface of serum cholinesterase. Biochim. biophys. Acta 13: 251-259.

Berman, H. A. and Decker, M. M. (1986) Kinetic, equilibrium and spectroscopic studies on cation association at the active center of acetylcholinesterase: topographic distinction between trimethyl and trimethylammonium sites. Biochem. biophys. Acta 872: 125-133.

Boopathy, R. and Balasubramanian, A. S. (1985) Chemical modification of the bifunctional human serum pseudocholinesterase. Effect on the pseudocholinesterase and acyl arylamidase activities. Eur. J. Biochem. 151: 351-360.

Boopathy, R. and Balasubramanian, A. S. (1987) A peptidase activity exhibited by human serum pseudocholinesterase. Eur. J. Biochem. 162: 191-197.

BRIMIJOIN, S. and HAMMOND, P. (1988) Butyrylcholinesterase in human brain and acetylcholinesterase in human plasma: trace enzymes measured by two-site immunoassay. J. Neurochem. 51: 1227-1231.

Brimijoin, S., MinTz, K. P. and Alley, M. C. (1983) Production and characterization of separate monoclonal antibodies to human acetylcholinesterase and butyrylcholinesterase. Molec. Pharmac. 24: 513-520.

Brown, S. S., Kalow, W., Pilz, W., Whittaker, M. and WORONICK, C. L. (1981) The plasma cholinesterases: a new perspective. Adv. clin. Chem. 22: 1-123.

Chan, L. M., Himel, C. M. and Main, A. R. (1974) Active-site-directed fluorescent probes in the kinetics and spectroscopy of purified horse serum cholinesterase. Biochemistry 13: 86-90.

Chatonnet, A. and Masson, P. (1985) Study of the peptidasic site of cholinesterase: preliminary results. FEBS Lett. 182: 493-498.

Chatonnet, A. and Masson, P. (1986) Is the peptidase activity of highly purified human plasma cholinesterase due to a specific cholinesterase isoenzyme or a contaminating dipeptidylaminopeptidase? Biochemie 68: 657-667.

Clark, S. W., Glaubiger, G. A. and La Du, B. N. (1968) Properties of plasma cholinesterase variants. Ann. N.Y. Acad. Sci. 151: 710-722.

Cohen, J. A., Oosterbaan, R. A., Jansz, H. S. and Berends, F. (1959) The active site of esterases. J. cell. comp. Physiol. 54 (Suppl. 1): 231-244.

COhen, P. J., Reynolds, R. C. and Naidl, J. (1970) A simple test for abnormal pseudocholinesterase. Anesthesiology 32: $281-282$.

DAS, P. K. and Liddell, J. (1970) Purification and properties of human serum cholinesterase. Biochem. J. 116: 875-881.

Davies, R. O., Marton, A. V. and Kalow, W. (1960) The action of normal and atypical cholinesterase of human serum upon a series of esters of choline. Can. J. Biochem. Physiol. 38: 545-551.

DevenYl, P. (1989) Cocaine complications and pseudocholinesterase. Ann. int. Med. 110: 167-168.

Doenicke, A., Gurtner, T., Kreutzberg, G., Remes, I., SPIEss, W. and Steinbereithner, K. (1963) Serum cholinesterase anenzymia. Report of a case confirmed by 
enzyme-histological examination of liver-biopsy specimen. Acta anaesth. scand. 7: 59-68.

Downs, J. R. (1966) Atypical cholinesterase activity: its importance in dentistry. J. oral Surg. 24: 256-257.

ECKerson, H. W., Oseroff, A., Lockridge, O. and LA Du, B. N. (1983a) Immunological comparison of the usual and atypical human serum cholinesterase phenotypes. Biochem. Genet. 21: 93-108.

Eckerson, H. W., Wyte, C. M. and LA Du, B. N. (1983b) The human serum paraoxonase/arylesterase polymorphism. Am. J. hum. Genet. 35: 1126-1138.

Evans, R. T. and Wardell, J. (1984) On the identification and frequency of the $J$ and $K$ cholinesterase phenotypes in a Caucasian population. J. med. Genet. 21: 99-102.

Fisher, D. M., Caldwell, J. E., Sharma, M. and Wiren, J. E. (1988) The influence of bambuterol (carbamylated terbutaline) on the duration of action of succinylcholine-induced paralysis in humans. Anesthesiology 69: $757-759$.

Foldes, F. F., Davidson, G. M., Duncalf, D. and Kuwabara, S. (1965) The intravenous toxicity of local anesthetic agents in man. Clin. Pharmac. Ther. 6: 328-335.

Garry, P., Dietz, A. A., Lubrano, T., Ford, P. C., JAMES, K. and RuBinstein, H. M. (1976) New allele at cholinesterase locus 1. J. med. Genet. 13: 38-42.

GibNey, G., MacPhee-Quigley, K., Thompson, B., Vedvick, T., Low, M. G., TAYlor, S. S. and TaYlor, P. (1988) Divergence in primary structure between the molecular forms of acetylcholinesterase. J. biol. Chem. 263: $1140-1145$.

Goedde, H. W., Held, K. R. and Altland, K. (1968) Hydrolysis of succinyldicholine and succinylmonocholine in human serum. Molec. Pharmac. 4: 274-287.

Hall, L. M. C. and SPIERER, P. (1986) The Ace locus of Drosophila melanogaster: structural gene for acetylcholinesterase with an unusual $5^{\prime}$ leader. EMBO J.5: 2949-2954.

HARris, H. (1980) The Principles of Human Biochemical Genetics (3rd Edn), pp. 159-172, Elsevier, Amsterdam.

HARRIS, H. and WhITTAKER, M. (1961) Differential inhibition of human serum cholinesterase with fluoride: recognition of two new phenotypes. Nature 191: 496-498.

Hasan, F. B., Cohen, S. G. and Cohen, J. B. (1980) Hydrolysis by acetylcholinesterase: apparent molal volumes and trimethyl and methyl subsites. J. biol. Chem. 255: 3898-3904.

Halpt, H., Heide, K., Zwisler, O. and Schwick, H. G. (1966) Isolierung und physikalisch-chemische Charakterisierung der cholinesterase aus Humanserum. Blut 14: $65-75$.

Heilbron, E. (1965) Action of fluoride on cholinesterase. In ritro reactivation of cholinesterases inhibited by organophosphorus compounds. Biochem. Pharmac. 14: $1363 \cdots 1373$.

Hersh, L. B., RaJ, P. P. and Ohlweiler, D. (1974) Kinetics of succinyldithiocholine hydrolysis by serum cholinesterase: comparison to dibucaine and succinylcholine numbers. J. Pharmac, exp. Ther. 189: 544-549.

Hoefnagel, D.. Harris, N. A. and Kim, T. H. (1979) Transient respiratory depression of the newborn. Its occurrence after succinylcholine administration to the mother. Am. J. Dis. Child 133: 825-826.

KabaChNiK, M. I., BrestKIN, A. P. Godovikov, N. N., Michelson, M. J., Rozengart, E. V. and Rozengart, V. I. (1970) Hydrophobic areas on the active surface of cholinesterases. Pharmac. Rer. 22: 355-388.

Kaemmer, D., Neubert, K., Demlth, H. U. and Barth, A. (1986) Contamination of highly purified human serum cholinesterase by dipeptidyl peptidase IV causing hydrolysis of substance P. Pharmazie 41: 494-496.

KaLOW W. (1956) Familial incidence of low pseudocholinesterase level. Lancet 2: $576 \cdot 577$.
Kalow, W. (1962a) Pharmacogenetics, Heredity and the Response to Drugs, pp. 69-93, W. B. Saunders, Philadelphia.

Kalow W. (1962b) Esterase action. In: Proc. Ist Int. Pharmac. Meet. Metabolic Factors Controlling Duration of Drug Action, Vol. 6, pp. 137-147, BrodIE, B. B. and Erdos, E. G. (eds). The Macmillan Publishing Co, New York.

KaLOW, W. and Davies, R. O. (1958) The activity of various esterase inhibitors towards atypical human serum cholinesterase. Biochem. Pharmac. 1: 183-192.

Kalow, W. and Genest, K. (1957) A method for the detection of atypical forms of human serum cholinesterase. Determination of dibucaine numbers. Can. $J$. Biochem. Physiol. 35: 339-346.

KaLOW, W. and GUNN, D. R. (1957) The relation between dose of succinylcholine and duration of apnea in man. J. Pharmac. exp. Ther. 120: 203-214.

KaLOW, W. and LindSAY, H. A. (1955) A comparison of optical and manometric methods for the assay of human serum cholinesterase. Can. J. Biochem. Physiol. 35: $568-574$.

Kalow, W. and Staron, N. (1957) On distribution and inheritance of atypical forms of human serum cholinesterase as indicated by dibucaine numbers. Can. $J$. Biochem. Physiol. 35: 1305-1320.

Khoury, G. F., Brill, J., Walts, L. and Busuttil, R. W. (1987) Atypical serum cholinesterase eliminated by orthotopic liver transplantation. Anesthesiology 67: 273-274.

KiefFer, B., Goeldner, M., Hirth, C., Aebersold, R. and ChANG, J. Y. (1986) Sequence determination of a peptide fragment from electric eel acetylcholinesterase, involved in the binding of quaternary ammonium. FEBS Lett. 202: 91-96.

KorZA, G. and Ozols, J. (1988) Complete covalent structure of $60-\mathrm{kDa}$ esterase isolated from 2,3,7,8-tetrachloridibenzo-p -dioxin-induced rabbit liver microsomes. $J$. biol. Chem. 263: 3486-3495.

Krause, A., Lane, A. B. and Jenkins, T. (1988) A new high activity plasma cholinesterase variant. $J$. med. Genet. 25 : 677-681.

KRUPKA, R. M. (1966a) Chemical structure and function of the active center of acetylcholinesterase. Biochemistry $\mathbf{5}$ : 1988-1998.

KRUPKA, R. M. (1966b) Fluoride inhibition of acetylcholinesterase. Molec. Pharmac. 2: 558-569.

Kuhnert, B. R., Philipson, E. H., Pimental, R. and KUHNERT, P. M. (1982) A prolonged chloroprocaine epidural block in a postpartum patient with abnormal pseudocholinesterase. Anesthesiology 56: 477-478.

KuTtY, K. M., REDHEendRAN, R. and MuRPHY, D. (1977) Serum cholinesterase: function in lipoprotein metabolism. Experientia 33: 420-422.

LAYER, P. G. and SPORNs, O. (1987) Spatiotemporal relationship of embryonic cholinesterases with cell proliferation in chicken brain and eye. Proc, natn. Acad. Sci. U.S.A. 84: 284-288.

LeE, E. Y. H. and LeE, W. H. (1986) Molecular cloning of the human esterase D gene, a genetic marker of retinoblastoma. Proc. natn. Acad. Sci. U.S.A. 83: 6573-6577.

Lee-Son, S., Pilon, R. N., Nahor, A. and Waud, B. E. (1975) Use of succinylcholine in the presence of atypical cholinesterase. Anesthesiology 43: 493-496.

Liddell, J., Lehmanin, H. and Silk, E. (1962) A silent pseudocholinesterase gene. Nature 193: 56l-562.

LOCKRIDGE, O. (1982) Substance $P$ hydrolysis by human serum cholinesterase. $J$. Neurochem. 39: 106-110.

LOCKRIDGE O. and LA DU, B. N. (1978) Comparison of atypical and usual human serum cholinesterase. Purification, number of active sites, substrate affinity, and turnover number. J. biol. Chem. 253: 361-366.

Lockridge, O. and LA DU, B. N. (1982) Loss of the interchain disulfide peptide and dissociation of the tetramer 
following limited proteolysis of native human serum cholinesterase. J. biol. Chem. 257: 12012-12018.

LOCKRIDGE, O. and LA DU, B. N. (1986) Amino acid sequence of the active site of human serum cholinesterase from usual, atypical, and atypical-silent genotypes. Biochem. Genet. 24: 485-498.

Lockridge O., Eckerson, H. W. and LA Du, B. N. (1979) Interchain disulfide bonds and subunit organization in human serum cholinesterase. J. biol. Chem. 254 8324-8330.

LOCKRIDGe, O., Mottershaw-Jackson, N., Eckerson, H. W. and LA Du, B. N. (1980) Hydrolysis of diacetylmorphine (heroin) by human serum cholinesterase. J. Pharmac. exp. Ther. 215: 1-8.

Lockridge O., Adkins, S. and LA DU, B. N. (1987a) Location of disulfide bonds within the sequence of human serum cholinesterase. J. biol. Chem. 262: 12945-12952.

Lockridge, O., Bartels, C. F., Vaughan, T. A., Wong, C. K., Norton, S. E. and Johnson, L. L. (1987b) Complete amino acid sequence of human serum cholinesterase. J. biol. Chem. 262: 549-557.

MacPhee-Quigley, K., Vedvick, T. S., Taylor, P. and TAYLOR, S. S. (1986) Profile of the disulfide bonds in acetylcholinesterase. J. biol. Chem. 261: 13565-13570.

Majumdar, R., Jayanthi, L. D. and Balasubramanian, A. S. (1988) A peptidase activity associated with acetylcholinesterase from electric eel and sheep basal ganglia. Indian J. Biochem. Biophys. 25: 303-312.

Mbugua, P. M. and Karlsson, E. (1985) Fasciculins from Dendroaspis angusticeps venom and their effect on cholinesterases. Toxicon 23: 595.

McGuire, M. C., Nogueira, C. P., Bartels, C. F., Lightstone, H., HajRa, A., Van Der Spek, A. F, L. LOCKRIDGe, O. and LA DU, B. N. (1989) Identification of the structural mutation responsible for the dibucaineresistant (atypical) variant form of human serum cholinesterase. Proc. natn. Acad. Sci. U.S.A. 86: 953-957.

Mctiernan, C., Adkins, S., Chatonnet, A., Vaughan, T. A., Bartels, C. F., Kott, M., Rosenberry, T. L., LA Du, B. N. and Lockridge, O. (1987) Brain cDNA clone for human cholinesterase. Proc. natn. Acad. Sci. U.S.A. 84: $6682-6686$.

MYers, C., LockridGe, O. and LA Du, B. N. (1982) Hydrolysis of methylprednisolone acetate by human serum cholinesterase. Drug Metab. Dispos. 10: 279-280.

Nausch, I. and Heymann, E. (1985) Substance P in human plasma is degraded by dipeptidyl peptidase IV, not by cholinesterase. J. Neurochem. 44: 1354-1357.

Neituich, H. W. (1966) Increased plasma cholinesterase activity and succinylcholine resistance: a genetic variant. J. clin. Invest. 45: 380-387.

Oakeshott, J. G., Collet, C., Phillis, R. W., Nielsen, K. M., Russell, R. J., Chambers, G. K., Ross, V. and Richmond, R. C. (1987) Molecular cloning and characterization of esterase-6, a serine hydrolase of Drosophila. Proc. natn. Acad. Sci. U.S.A. 84: 3359-3363.

Ostergaard, D., Viby-Mogensen, J., Hanel, H. K. and SKovgaARd, L. T. (1988) Half-life of plasma cholinesterase. Acta Anaesth. scand. 32: 266-269.

Prody, C. A., Zevin-Sonkin, D., Gnatt, A., Goldberg, O. and SOREQ, H. (1987) Isolation and characterization of full-length cDNA clones coding for cholinesterase from fetal human tissues. Proc. natn. Acad. Sci. U.S.A. 84: 3555-3559.

Raj, P. P., Rosenblatt, R., Miller, J., Katz, R. L. and Carden, E. (1977) Dynamics of local-anesthetic compounds in regional anesthesia. Anesth. Analg. 56: 110-117.

RakonCZaY, Z. (1988) Cholinesterase and its molecular forms in pathological states. Prog. Neurobiol. 31: 311-330.

Ralston, J. S., Main, A. R., Kilpatrick, B. F. and Chasson, A. L. (1983) Use of procainamide gels in the purification of human and horse serum cholinesterases. Biochem. J. 211: 243-250.

RoBson, E. B. and HaRris, H. (1966) Futher data on the incidence and genetics of the serum cholinesterase phenotype C5 +. Am. J. hum. Genet. 29: 403-408.

Rubinstein, H. M., DieTz, A. A., Hodges, L. K., Lubrano, T. and Czebotar, V. (1970) Silent cholinesterase gene: variations in the properties of serum enzyme in apparent homozygotes. J. clin. Invest. 49: 479-486.

Rubinstein, H. M., Dietz, A. A. and Lubrano, T. (1978) $E_{1}^{k}$, another quantitative variant at cholinesterase locus 1 . J. med. Genet. 15: 27-29.

Rush, R. S., Ralston, J. S. and Wolfe, A. D. (1985) Aprophen: a substrate and inhibitor of butyrylcholinesterase and carboxylesterases. Biochem. Pharmac. 34: 2063-2068.

Savarese, J. J., Hassan, H. H., Basta, S. J., Embree, P. B., Scott, R. P. F., Sunder, N., Weakly, J. N., Wastila, W. B. and EL-SAYAD, H. A. (1988) The clinical neuromuscular pharmacology of mivacurium chloride (BW 1090U). A short-acting nondepolarizing ester neuromuscular blocking drug. Anesthesiology 68: 723-732.

Schumacher, M., Camp, S., Maulet, Y., Newton, M. MacPheE-Quigley, K., Taylor, S. S., Friedmann, T. and TAYLOR, P. (1986) Primary stucture of Torpedo californica acetylcholinesterase deduced from its cDNA sequence. Nature 319: 407-409.

Scotr, E. M. and Powers, R. F. (1974) Properties of the C5 variant form of human serum cholinesterase. Am. J. hum. Genet. 26: 189-194.

Shows, T. B., McAlpine, P. J., Boucheix, C., Collins, F. S., Conneally, P. M., Frezal, J., Gershowitz, H., Goodfellow, P. N., Hall, J. G., Issitt, P., Jones, C. A., Knowles, B. B., Lewis, M., McKusick, V. A., Meisler, M., Morton, N. E., Rubinstein, P., Schanfield, M. S., Schmickel, R. D., Skolnick, M. H., Spence, M. A., Sutherland, G. R., Traver, M., Van Cong, N. and Willard, H. F. (1987) Guidelines for human gene nomenclature. An International System for Human Gene Nomenclature (ISGN, 1987). Cytogenet. Cell Genet. 46: $11-28$.

Sikorav, J. L., Krejci, E. and Massoulie, J. (1987) cDNA sequences of Torpedo marmorata acetylcholinesterase: primary structure of the precursor of a catalytic subunit; existence of multiple 5 -untranslated regions. $E M B O J .6$ : 1865-1873.

Sikorav, J. L., Duval, N., Anselmet, A., Bon, S., Krejci, E., Legay, C., Osterlund, M., Reimund, B. and Massoulie, J. (1988) Complex alternative splicing of acetylcholinesterase transcripts in Torpedo electric organ; primary structure of the precursor of the glycolipidanchored dimeric form. EMBO J. 7: 2983-2993.

Silman, I. and Futerman, A. H. (1987) Modes of attachment of acetylcholinesterase to the surface membrane. Eur. J. Biochem. 170: 11-22.

Simpson, N. E. and Elliott, C. R. (1981) Cholinesterase Newfoundland: a new succinylcholine-sensitive variant of cholinesterase at locus 1. Am. J. hum. Genet. 33: 366-374.

Small, D. H. (1988) Serum acetylcholinesterase possesses trypsin-like and carboxypeptidase B-like activity. Neurosci. Lett. 95: 307-312.

Small, D. H., Ismael, Z. and ChubB, I. W. (1987) Acetylcholinesterase exhibits trypsin-like and metallopeptidaselike activity in cleaving a model peptide. Neuroscience 21: $991-995$.

Smyth, K. K., De la Hoz, D. M., Christner, C. E., Rush, R. S., De LA Hoz, F. and Doctor, B. P. (1988) Amino acid sequence studies on fetal bovine serum acetylcholinesterase. FASEB J. 2: A1745.

SOREQ, H., ZAMIR, R., ZEVIN-SONKIN, D. and ZAKUT, H. (1987) Human cholinesterase genes localized by hybridization to chromosomes 3 and 16. Hum. Genet. 77: 325-328. 
Stewart, D. J., Inaba, T., TANG, B. K. and Kalow, W. (1977) Hydrolysis of cocaine in human plasma by cholinesterase. Life Sci. 20: 1557-1564.

Tomlinson, G. and KinsCH, E. M. (1989) $S$-mercuric$N$-dansyl-cysteine labels the free sulfhydryl groups of human serum cholinesterase. Biochem. biophys. Acta 158: 503-507.

TuneK, A. and Svensson, L. A. (1988) Bambuterol, a carbamate ester prodrug of terbutaline, as inhibitor of cholinesterases in human blood. Drug Metab. Dispos. 16: 759-764.

TuneK, A., Levin, E. and Svensson, L. A. (1988) Hydrolysis of ${ }^{3} \mathrm{H}$-bambuterol, a carbamate prodrug of terbutaline, in blood from humans and laboratory animals in vitro. Biochem. Pharmac. 37: 3867-3876.

VAlentino, R. J., Lockridge, O., EcKerson, H. W. and LA Du, B. N. (1981) Prediction of drug sensitivity in individuals with atypical serum cholinesterase based on in vitro biochemical studies. Biochem. Pharmac. 30: 1643-1649.

Venta, P. J., Montgomery, J. C. and Tashian, R. E. (1987) Molecular genetics of carbonic anhydrase isozymes. In: Isozymes: Current Topics in Biological and Medical Research, Vol. 14, pp. 59-72, RatTAzZI, M. C., Scandalios, J. G. and WhitT, G. S. (eds) Alan R. Liss Inc, New York.

ViBY-Mogensen, J. (1980) Correlation of succinylcholine duration of action with plasma cholinesterase activity in subjects with the genotypically normal enzyme. Anesthesiology 53: 517-520.

VIBY-MOGENSEN, J. (1981a) Succinylcholine neuromuscular blockade in subjects heterozygous for abnormal plasma cholinesterase. Anesthesiology 55: 231-235.

VibY-MogenSEN, J. (1981b) Succinylcholine neurmuscular blockade in subjects homozygous for atypical plasma cholinesterase. Anesthesiology 55: 429-434.
VIBy-Mogensen, J. (1983) Cholinesterase and succinylcholine. Dan. med. Bull. 30: 129-150.

VIBY-MOGENSEN, J. (1985) Abnormal plasma cholinesterase activity: implications for the anaesthetist. In: Lectures In Anaesthesiology, pp. 63-73, ZoRAB, J. S. M. (ed.) Blackwell Scientific Publications, Oxford.

Viby-Mogensen, J. and Hanel, H. K. (1978) Prolonged apnoea after suxamethonium. An analysis of the first 225 cases reported to the Danish Cholinesterase Research Unit. Acta anaesth. scand. 22: 371-380.

WhITTAKER, M. (1968) The pseudocholinesterase variants. Differentiation by means of alkyl alcohols. Acta Genet. Basel 18: 325-334.

WhitTaker, M. (1980) Plasma cholinesterase variants and the anaesthetist. Anaesthesia 35: 174-197.

WhitTaker, M. (1986) Cholinesterase. Monographs in Human Genetics, Vol. 11, BeckMan, L. (ed.) Karger, Basel, Switzerland.

WhITTAKER, M. and BRITTEN, J. (1981) Differential inhibition of plasma cholinesterase variants using the dibutyrate analogue of pancuronium bromide. Hum. Hered. 31: $242-247$.

Whittaker, M. and Britten, J. J. (1985) Plasma cholinesterase variants. Family studies of the $E_{1}^{k}$ gene. Hum. Hered. 35: 364-368.

WhitTAKeR, M. and BritTen, J. J. (1987) $E_{1}^{\mathrm{h}}$, a new allele at cholinesterase locus 1. Hum. Hered. 37: 54-58.

YanG, F., Lum, J. B., MCGill, J. R., Moore, C. M., NAYloR, S. L., VAN BRaGt, P. H., Baldwin, W. D. and Bowman, B. H. (1984) Human transferrin: cDNA characterization and chromosomal localization. Proc. natn. Acad. Sci. U.S.A. 81: 2752-2756.

Zsigmond, E. K. and EILderton, T. E. (1968) Abnormal reaction to procaine and succinylcholine in a patient with inherited atypical plasma cholinesterase: case report. Can. Anaesth. Soc. J. 15: 498-500. 